REALA, número 13, abril-septiembre de 2020

Sección: COMUNICACIONES Y COMENTARIOS JURISPRUDENCIALES

Recibido: 16-09-2019

Modificado: 02-12-2020

Aceptado: 26-11-2019

DOI: $10.24965 /$ reala.i13.10728

Páginas: $110-130$

\title{
Castilla y León vacía (vaciada): esperando a Ulises Castilla y León empty: waiting for Ulises
}

\author{
Santiago A. Bello Paredes \\ Universidad de Burgos (España) \\ ORCID: https://orcid.org/0000-0002-1324-0965 \\ sbello@ubu.es
}

\section{NOTA BIOGRÁFICA}

Catedrático de Derecho Administrativo por la Universidad de Burgos (2018). Decano de la Facultad de Derecho desde 2016. Director del Instituto de Administración Pública de la Universidad de Burgos (20082009). Secretario General de la Universidad de Burgos (2006-2008). Sus líneas de investigación son: derecho local; derecho nuclear y sostenibilidad energética; sociedad de la información y TIC; desarrollo sostenible. Es autor de cuarenta y cinco publicaciones entre libros y capítulos de libro y de treinta artículos en revistas científicas indexadas, además de Coordinador y Director de diversos libros y obras colectivas.

\section{RESUMEN}

Este trabajo estudia la situación actual de la Comunidad Autónoma de Castilla y León, en la que se destaca el envejecimiento de su población diseminada en un gran número de municipios, que conduce a una necesidad insoslayable de implantación real y efectiva de las medidas legales necesarias para impedir el retroceso poblacional, que se viene imponiendo desde los años cincuenta del siglo XX.

\section{PALABRAS CLAVE}

Administración local; despoblación; reforma local; Castilla y León.

\begin{abstract}
This work study the current situation of the Autonomous Community of Castilla y León, with a situation of evident aging of its spreaded population in a large number of municipalities, which leads to an inescapable need for real and effective implementation of the necessary legal measures to prevent the population's regression, which has been imposed since the fifties of the twentieth century.
\end{abstract}

\section{KEYWORDS}

Local government; depopulation; local reform; Castilla y León.

\section{SUMARIO}

INTRODUCCIÓN. 1. CASTILLA Y LEÓN EN LA ESPAÑA VACÍA: EL OVILLO DE LA LANA DE PENÉLOPE. 2. LAS REFORMAS EN CASTILLA Y LEÓN: TEJER Y DESTEJER. 2.1. LAS COMPETENCIAS SOBRE LA PLANTA LOCAL. 2.2. LA REFORMA LOCAL DESDE EL PARADIGMA DE LA ORDENACIÓN DEL TERRITORIO. 3. PROPUESTAS DE SOLUCIÓN. 3.1. REFORMA DE LA PLANTA LOCAL O MANTENIMIENTO DE LAACTUAL ESTRUCTURA TERRITORIAL EN CASTILLA Y LEÓN: EL PARADIGMA DE LAS MIG. 3.2. REFORMA LOCAL Y ORGANIZACIÓN PERIFÉRICA DE LA JUNTA DE CASTILLA Y LEÓN. 3.3. APUESTA POR LAS INFRAESTRUCTURAS TECNOLÓGICAS. REFERENCIAS BIBLIOGRÁFICAS. 


\section{INTRODUCCIÓN}

Antes de abordar el tema objeto de este trabajo", debemos hacer una referencia expresa a su título: "Castilla y León vacía (vaciada)", porque se puede utilizar tanto la palabra vacía, como vaciada. Según la RAE, la expresión vacía, en una de sus acepciones, en la que se refiere concretamente a un lugar físico, significa literalmente que: «está con menos gente de la que puede concurrir a él»; mientras que la palabra vaciada es contemplada como el resultado de una acción de vaciar. Y ambas expresiones identifican claramente la situación de esta Comunidad Autónoma, pues para llegar al momento actual (vacía), han acontecido una serie de circunstancias que han conducido a dejarla (vaciada), y ello como un fenómeno poblacional iniciado en los años cincuenta del siglo veinte, sin que se hayan adoptado las medidas suficientes para paliar o revertir esta situación.

Sea como fuere, esta es la situación en la que se encuentra el espacio físico de Castilla y León en particular, y grandes espacios territoriales de España en general.

No puede negarse que nos encontramos ante uno de los problemas más importantes a medio y largo plazo de España, que no sólo ha sido centro de la campaña electoral desarrollada en la primavera de este año 2019, sino que ha sido objeto de interpelaciones por el Defensor del Pueblo², reivindicaciones ciudadanas, etc.

Y este fenómeno no representa una situación nueva que haya aflorado en este siglo XXI, sino que, por el contrario, es ahora cuando se ha visto plasmado, reivindicado y empoderado como problema acuciante ${ }^{3}$.

En Europa también existe un fenómeno de despoblamiento de las zonas rurales, por ello no resulta extraño que desde la UE se haya venido reflexionando sobre esta situación con una finalidad prospectiva, como puede ser en el Dictamen del Comité Europeo de las Regiones, de fecha 16 de junio de 2016, "La respuesta de la UE al reto demográfico" (2017/C 017/08), DUE de 18 de enero de 2017). En este documento se realiza una descripción del cambio demográfico que se está desarrollando en Europa, al que se califica como uno de los mayores desafíos a los que se enfrenta la Unión Europea, con «el envejecimiento de la población, la disminución del número de jóvenes y una tasa de natalidad inferior» (apartado 1$)^{4}$.

Y pese a la habilitación normativa contenida en el artículo 174 del Tratado de Funcionamiento de la Unión Europea (TFUE), el cual establece que se prestará una «especial atención a las zonas rurales, a las zonas afectadas por una transición industrial y a las regiones que padecen desventajas naturales o demográficas graves y permanentes como, por ejemplo, las regiones más septentrionales con una escasa densidad de población y las regiones insulares, transfronterizas y de montaña», las respuestas que llegan desde la UE carecen de la contundencia suficiente para revertir esta situación.

Por eso en el citado Dictamen se concluye la necesidad de que la respuesta de la UE al cambio demográfico adopte «una visión amplia, coordinada e integradora, puesto que se trata de un tema transversal» (apartado 20), en el que efectúe un especial énfasis sobre las siguientes líneas de acción:

1. Priorizar la creación de oportunidades de apoyo y generación de vida para ayudar a atraer y retener población joven en todo el territorio.

2. Impulsar políticas favorables a la familia, en particular, mediante medidas que eliminen los obstáculos que desincentivan la paternidad, y que contribuyan a aumentar la tasa de natalidad, incorporar la perspectiva de género.

1 Este trabajo es el inicio de un conjunto de publicaciones con las que se pretende poner de manifiesto la situación de una gran parte de España que se integra en el concepto de la «España vacía» y las posibles soluciones que se propugnan, y se han articulado o están en vía de implantación, tanto por las autoridades autonómicas, como nacionales.

2 Órgano constitucional que ha iniciado una actuación con el Comisionado del Gobierno frente al Reto Demográfico y con las Comunidades Autónomas de Aragón, Castilla La Mancha, Castilla y León, Cataluña, Comunidad Valenciana, Extremadura, Galicia y La Rioja, para conocer los planes y actuaciones que manejan las administraciones para afrontar el reto demográfico y comenzar a revertir la situación en la denominada «España vacía».

3 Como dato estadístico, en el barómetro del CIS de febrero de 2019 (pregunta 24), se afirma que un 82,4\% de los encuestados sí conoce lo que es la despoblación en España, que un 88,5\% lo considera como un problema grave o muy grave (41,4\% lo considera muy grave y $47,1 \%$ grave.

4 Apuntando en el ámbito de la demografía que desde el año 2000, el crecimiento poblacional de Europa ha sido muy modesto en comparación con los 50 años anteriores: en torno al 0,5\% anual. En 2014, doce Estados miembros experimentaron pérdidas de población, mientras que en dieciséis se dio un crecimiento. Existen importantes diferencias entre el Este y el Oeste de Europa y también, aunque en menor medida, entre el Norte y el Sur. Incluso dentro de un mismo Estado son frecuentes las desigualdades regionales. En particular, se aprecia un patrón global de mayor crecimiento en las áreas urbanas que en las rurales en la mayoría de los países europeos. Las áreas rurales remotas experimentan desafíos demográficos en todo el continente. La reciente crisis económica ha acentuado la polarización de tendencias tanto a nivel europeo como nacional, así como los desafíos de pérdida de población a nivel regional, apartado 3 del citado Dictamen. 
3. Alentar la vida autónoma de las personas de edad avanzada y aumentar la esperanza de vida sana y reducir la dependencia.

4. Luchar contra la exclusión social que afrontan algunas capas de la población y promover nuevos esfuerzos que afiancen el reconocimiento de las tareas domésticas no remuneradas así como la implementación de políticas de conciliación de la vida profesional y familiar.

5. Apoyar políticas de inmigración en los Estados miembros.

Y para ello deberán ser las entidades locales y autonómicas las organizaciones territoriales que «deben estar plenamente capacitadas para aplicar con éxito las políticas de integración sobre el terreno, incluidos los pequeños municipios de las zonas rurales» (apartado 27 del Dictamen ).

Retomando la situación en España, nos encontramos ante amplios territorios de la España interior afectados por la despoblación, así como del envejecimiento de su población y, en algunos de ellos, de la propia población flotante. En este sentido, la despoblación es manifiesta, pues cada año mengua el número de habitantes en los municipios rurales.

El envejecimiento, por su parte, es una consecuencia evidente de la emigración y el éxodo rural que afectó al campo español desde 1959 y que supuso la salida de familias enteras y que ha continuado con la pérdida de población joven en busca de trabajo en la ciudad (Alario et al. 2018: 25).

Si analizamos la evolución de la población en España, se percibe un incremento en toda la secuencia 1900-2011 y a partir de este año un acusado descenso:

Figura 1. EVOLUción PORCENTUAL de LA POBLACIÓN EN ESPAÑa

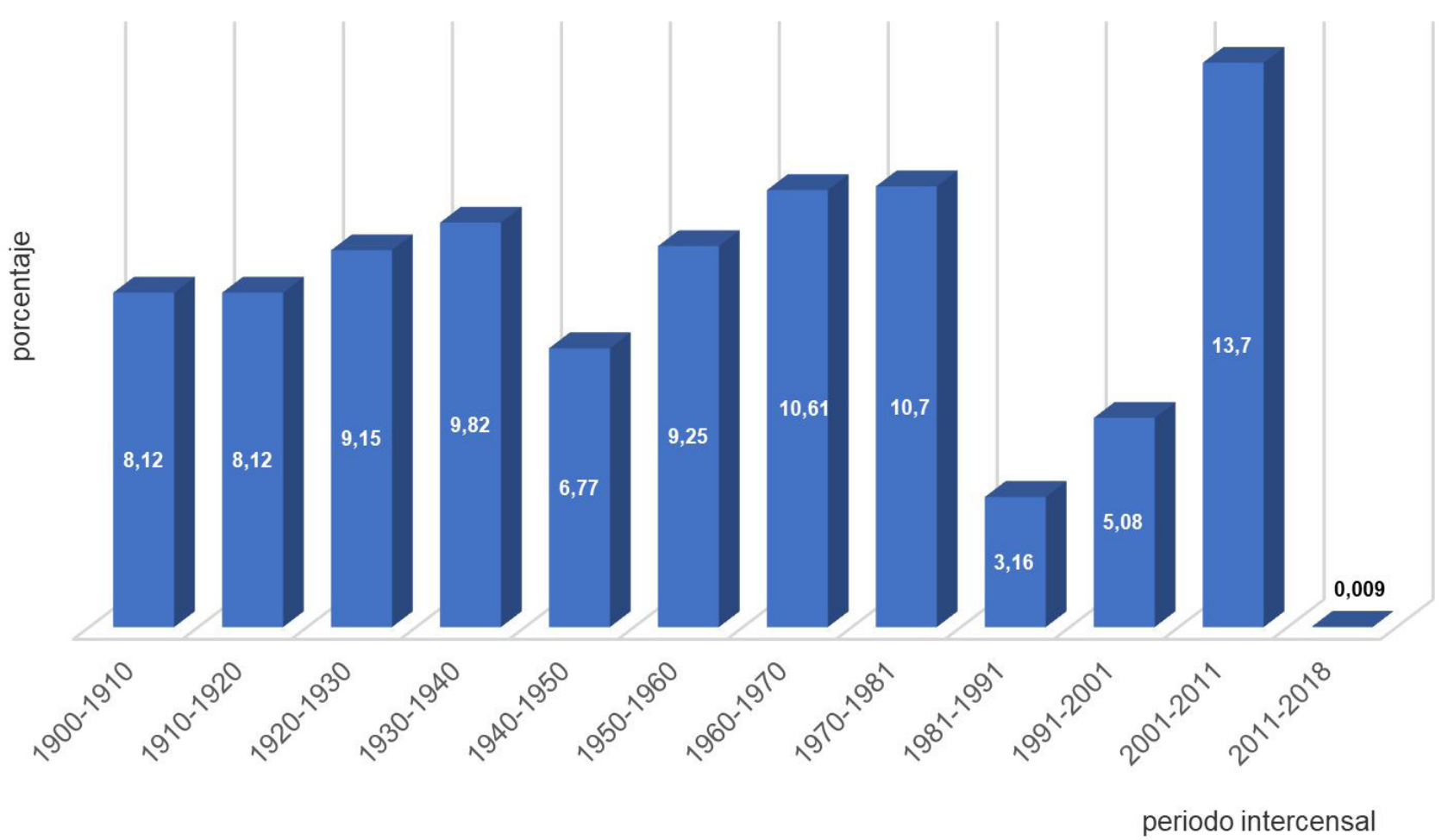

Fuente: Elaboración propia a partir de los datos INE Padrón Municipal de Habitantes.

Y si nos centramos en el periodo 2011-2018, la tasa de crecimiento negativo se distribuye de la siguiente forma por las diversas Comunidades Autónomas 5 .

5 Según los datos provisionales del Padrón Municipal de Habitantes, a fecha 1 de enero de 2019, ha existido un aumento a nivel nacional de 284.387 personas (un $0,6 \%$ ) respecto a los datos a 1 de enero de 2018 . En una perspectiva autonómica, en términos relativos, los mayores aumentos de población se registran en Illes Balears (1,8\%), Comunidad de Madrid (1,3\%) y Canarias (1,2\%); por el contrario Extremadura, Principado de Asturias y Castilla y León (todas ellas con un - $0,5 \%$ ) presentan los mayores descensos, según explica el INE en el "Avance de la Estadística del Padrón Continuo a 1 de enero de 2019. Datos provisionales". 
Figura 2. TASA de CRecimiento en España 2011-2018 por Comunidades Autónomas
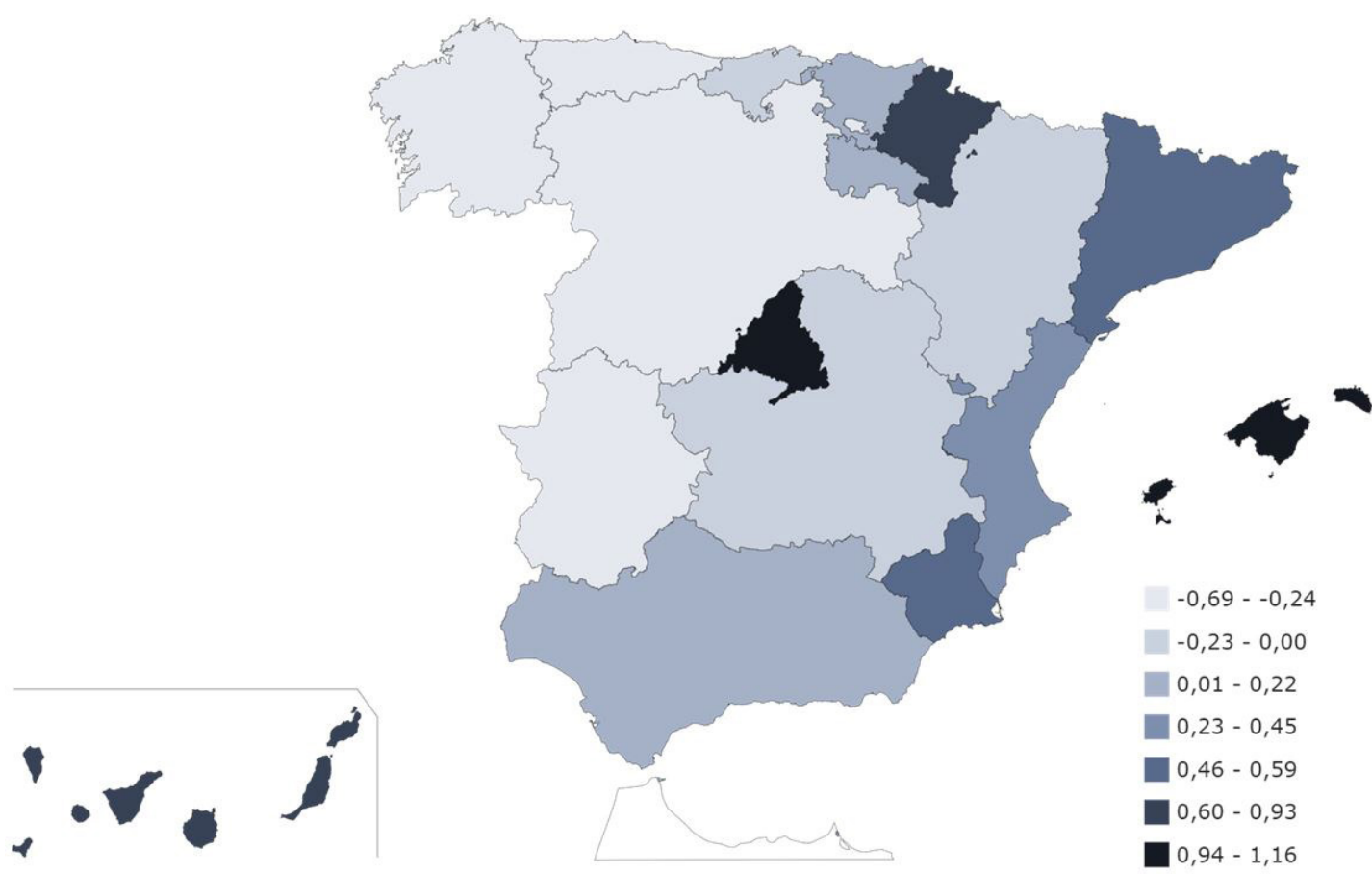

Fuente: INE, Padrón Municipal de Habitantes (2011-2018) .

\section{CASTILLA Y LEÓN EN LA ESPAÑA VACÍA: EL OVILLO DE LA LANA DE PENÉLOPE}

Si nos centramos en cuantificar la situación en Castilla y león en lo que se refiere a su evolución poblacional, así como al envejecimiento que presenta y, por último, a su lugar de residencia en los municipios, los resultados son especialmente preocupantes.

Así, en lo que se refiere a la población esta evolución presenta una línea descendente desde el año 2010, y acusadamente desde 2012:

Figura 3. Evolución de LA POBLACIÓN EN ESPAÑA 1998-2018

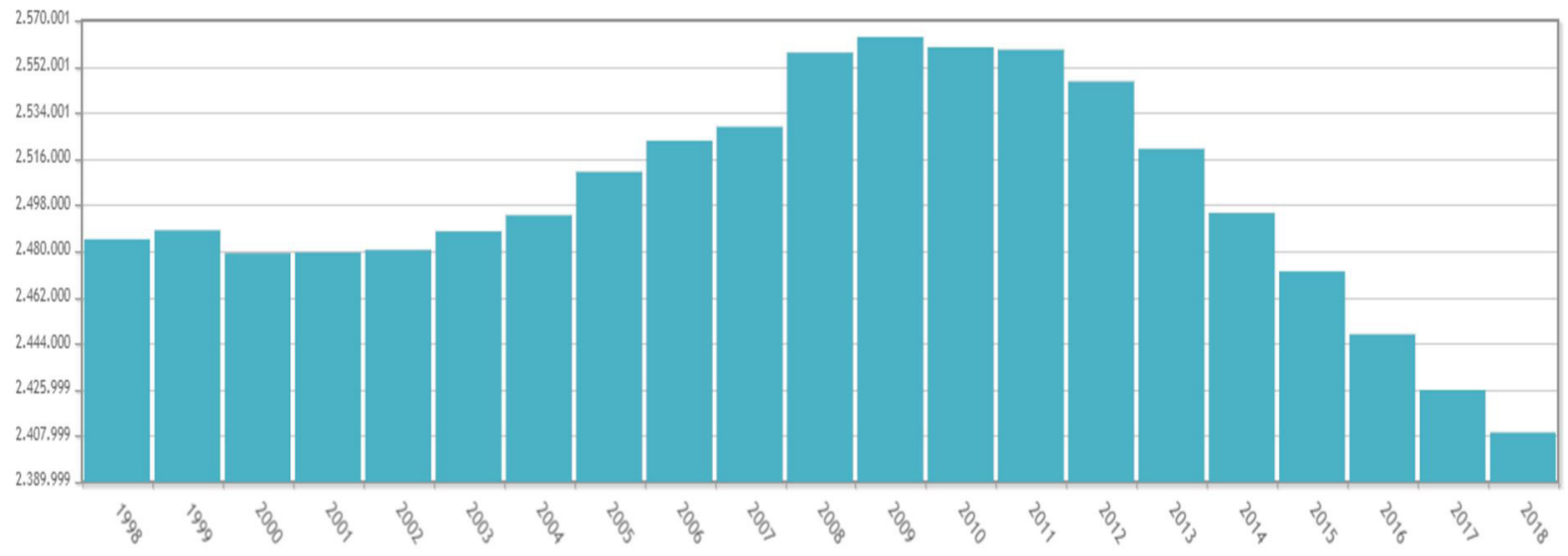

Fuente: INE, Padrón Municipal de Habitantes (1998-2018). 
Además, se puede advertir una preocupante situación de despoblación en Castilla y León, lo cual se evidencia de la "Evolución de la población por Provincia, Castilla y León y España. 1998-2018" (Dirección General de Presupuestos y Estadística de la Junta de Castilla y León, 2019). La mera lectura de la comparativa autonómica y estatal, pone de manifiesto un retroceso de la población en Castilla y León en 72.439 habitantes $(-2,92 \%)$, frente a un incremento de población en España de 6.870 .329 habitantes $(17,23 \%)$. La rotundidad de estos datos pone de manifiesto la existencia de una tendencia clara a la despoblación en Castilla y León en el periodo 1998-2018.

Por provincias, el mayor descenso se encuentra en León (42.619 habitantes y un descenso de 8,41\%) y Zamora (30.065 habitantes y un descenso 14,93\%), que no quedan compensados por el crecimiento de población en las provincias de Valladolid (27.822 habitantes y un 5,65\%) y de Burgos (10.715 habitantes y un $3,09 \%)$.

Y esta situación demográfica no tiene un carácter coyuntural (1998-2018), sino que es consecuencia de una situación anterior. De esta forma, en el periodo 1950-1998, se puede afirmar que el número de habitantes residentes ha descendido a 2.484.603, esto es, un índice 86 con relación a 1950 y un porcentaje de 6,2 sobre el total de población española, o sea 4 puntos menos que en 1950, lo que supone un descenso relativo más rápido en la segunda que en la primera mitad del siglo (xx) de la población regional comparada con la población española. Desde 1950 la pérdida de población ha sido de forma continuada, particularmente intensa en el intercenso 1960-70 (Prieto y López, 1999: 90).

En conclusión, mientras en el conjunto de España la población se duplica a lo largo del siglo XX, en Castilla y León apenas se crece en el mismo periodo, y se mantiene una tendencia a la pérdida desde 1960, sin que los cambios políticos y económicos hayan modificado significativamente esta tendencia (Molina, 2019: 6).

Pero si esta situación de pérdida poblacional no resultase especialmente preocupante, a ello se debe adicionar el específico panorama de la planta local en Castilla y León, el cual presenta un elevadísimo número de entidades territoriales.

Si efectuamos una cuantificación de las entidades locales más pequeñas, municipios y entidades submunicipales, la situación es la siguiente:

Tabla 1. Número de entidades locales en Castilla y León

\begin{tabular}{lcc}
\hline Provincias & Municipios & EATIM \\
\hline Ávila & 251 & 2 \\
\hline Burgos & 373 & 649 \\
\hline León & 213 & 1.228 \\
\hline Palencia & 195 & 225 \\
\hline Salamanca & 362 & 19 \\
\hline Segovia & 209 & 17 \\
\hline Soria & 183 & 55 \\
\hline Valladolid & 226 & 9 \\
\hline Zamora & 248 & 14 \\
\hline Total & $\mathbf{2 . 2 6 0}$ & $\mathbf{2 . 2 1 8}$ \\
\hline
\end{tabular}

Fuente: Elaboración propia a partir de los datos del Registro de entidades locales. Ministerio de Hacienda y Administraciones Públicas. 2019.

$\mathrm{Si}$, además, efectuamos una valoración de la población existente en estos municipios, con los últimos datos del Padrón Municipal, la situación es realmente preocupante en esta Comunidad Autónoma: 
REALA. Nueva Época - N. ${ }^{\circ}$ 13, abril-septiembre 2020 - ISSN: 1989-8975 - DOI: 10.24965/reala.i13.10728 - [Págs. 110-130]

Castilla y León vacía (vaciada): esperando a Ulises

FIgURA 4. NÚMERO DE MUNICIPIOS POR TAMAÑo DE MUNICIPIO.

Estadística del Padrón Continuo, tamaño de municipio, Castilla y León

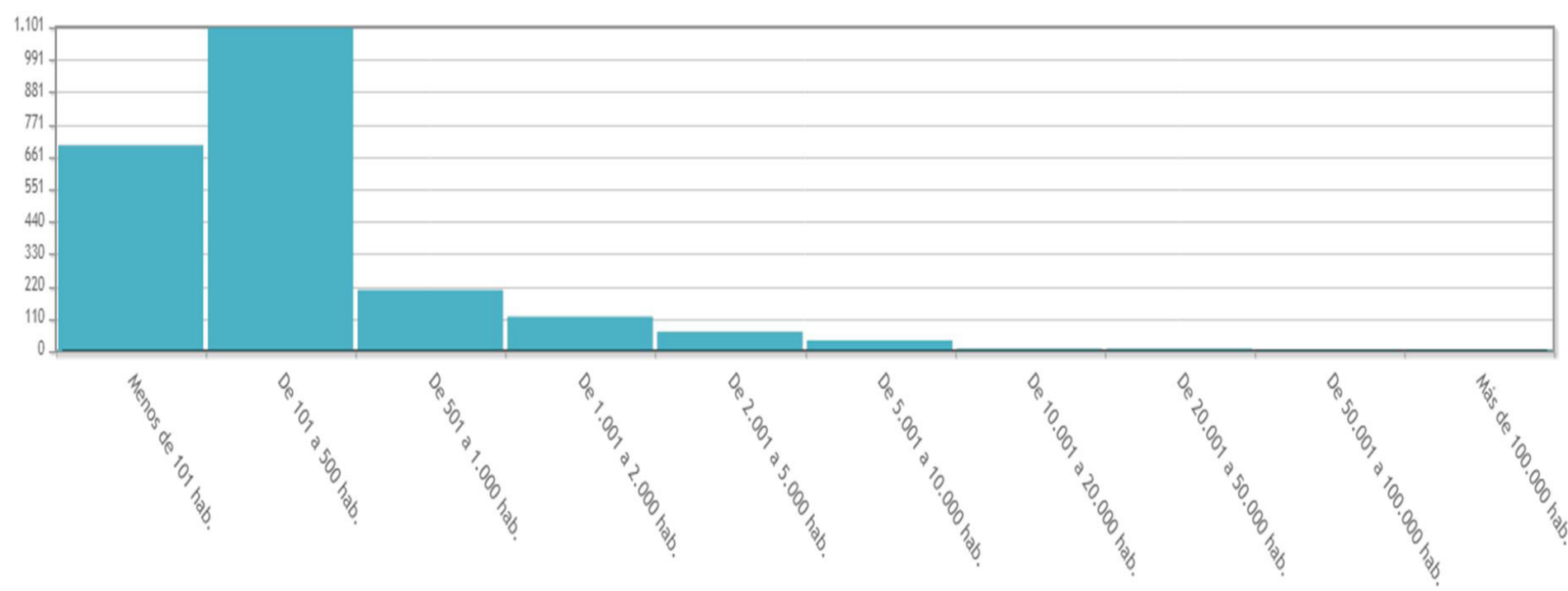

Fuente: INE, Estadística del Padrón Continuo a 1 de enero de 2019.

En este gráfico se observa que el mayor volumen del número de los municipios de Castilla y León es el de aquellos que no superan los 500 habitantes; en concreto, los municipios con menos de 101 habitantes son 692, y los que tienen entre 101 y 500 habitantes son 1.102 .

Lo que supone, en cifras relativas, que el $79,8 \%$ de los municipios en Castillas y León no superan los 100 habitantes. Y solo 9 municipios superan los 50.001 habitantes, de ellos, solo 4 superan los 100.000 habitantes.

Si analizamos la evolución del número de nacimientos en el intercenso 1975-2017, muestra un evidente descenso en Castilla y León.

Figura 5. Número de nacimientos en Castilla y León, 1975-2017

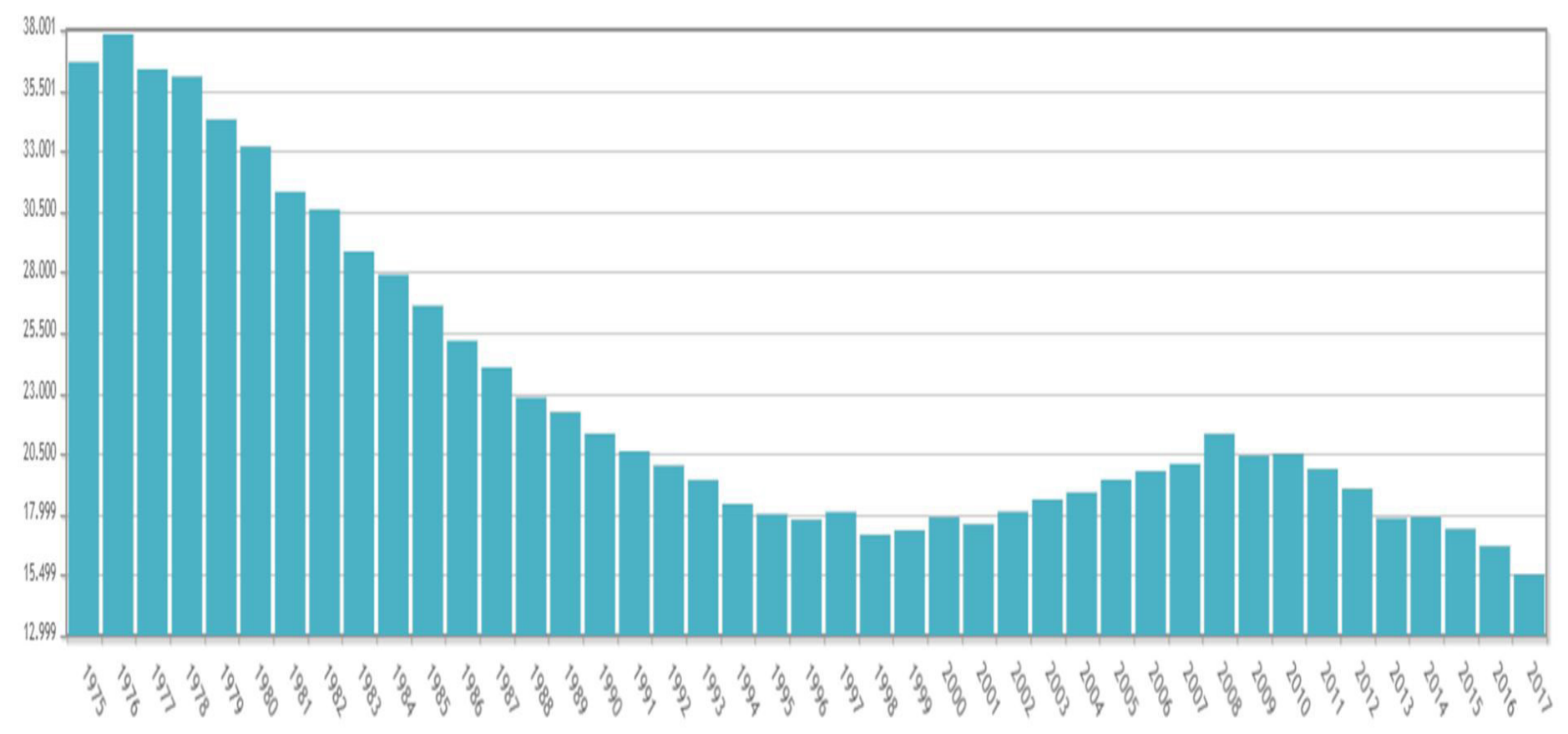

Fuente: INE, Movimiento natural de la población: nacimientos. 
REALA. Nueva Época - N. ${ }^{\circ}$ 13, abril-septiembre 2020 - ISSN: 1989-8975 - DOI: 10.24965/reala.i13.10728 - [Págs. 110-130]

Castilla y León vacía (vaciada): esperando a Ulises

Santiago A. Bello Paredes

Por último, la situación de la edad media de la población en los municipios es la siguiente:

Figura 6. EdAd MEdia de LA POBLACIÓN EN CASTILLA Y LEÓN POR TAMAÑo de MUNicipio

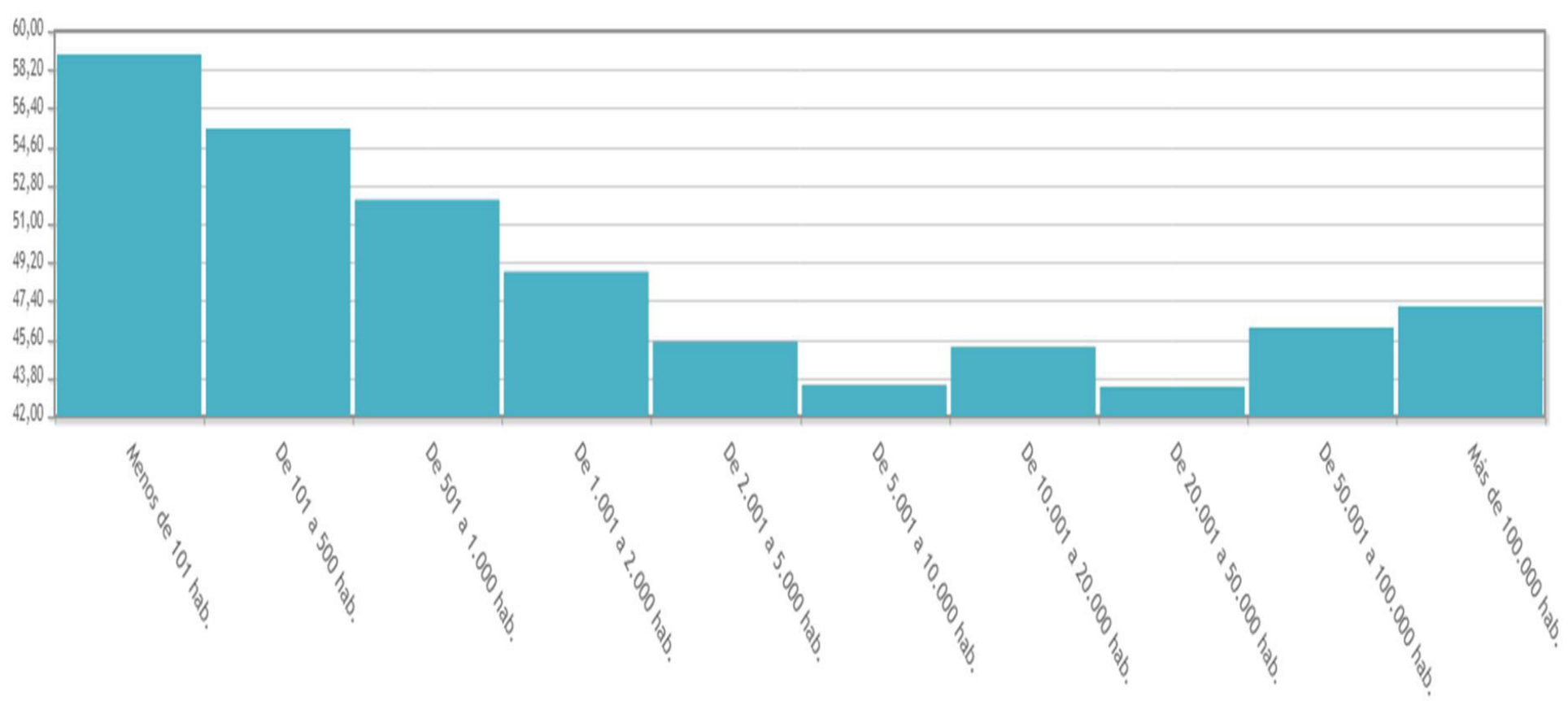

Fuente: INE, Estadística del Padrón Continuo a 1 de enero de 2019.

En definitiva, cuanto más pequeño es el municipio más envejecida es su población, llegando en los municipios de menos de 100 habitantes a tener una media de edad de 58,90 años y en los de 101 a 500 habitantes a la edad media de 55,44. La edad media menos elevada se encuentra en los municipios de 20.000 a 50.000 habitantes, con una edad de 45,25 años.

Curiosamente no es en las ciudades intermedias (Llop et al., 2019: 23) donde la edad media es menos elevada, sino en las pequeñas ciudades, las cuales en Castilla y León, incluyendo a las capitales de provincia sumarían un total de 51 , con una población entre 5.001 y más de 100.000 habitantes.

La distribución por provincias sería la siguiente ${ }^{6}$ :

TABla 2. Número de municipios en Castilla y León en función de su población

\begin{tabular}{lccccc}
\hline \multicolumn{1}{c}{ Población } & $\begin{array}{c}\text { De 5.001 } \\
\text { a 10.000 }\end{array}$ & $\begin{array}{c}\text { De 10.001 } \\
\text { a 20.000 }\end{array}$ & $\begin{array}{c}\text { De 20.001 } \\
\text { a 50.000 }\end{array}$ & $\begin{array}{c}\text { De 50.001 } \\
\text { a 100.000 }\end{array}$ & $\begin{array}{c}\text { Más } \\
\mathbf{1 0 0 . 0 0 1}\end{array}$ \\
\hline Ávila & 4 & 0 & 0 & 1 & 0 \\
\hline Burgos & 2 & 0 & 2 & 0 & 1 \\
\hline León & 6 & 3 & 1 & 1 & 1 \\
\hline Palencia & 4 & 0 & 0 & 1 & 0 \\
\hline Salamanca & 6 & 3 & 0 & 0 & 1 \\
\hline Segovia & 4 & 0 & 0 & 1 & 0 \\
\hline
\end{tabular}

6 Esta metodología resulta acorde con la legislación española, la cual considera como municipio rural, aquel que «posea una población residente inferior a las 5.000 habitantes y esté integrado en el medio rural» (artículo 3 de la Ley 45/2007, de 13 de diciembre, para el desarrollo sostenible del medio rural). 


\begin{tabular}{lccccc}
\hline Población & $\begin{array}{c}\text { De 5.001 } \\
\text { a 10.000 }\end{array}$ & $\begin{array}{c}\text { De 10.001 } \\
\text { a 20.000 }\end{array}$ & $\begin{array}{c}\text { De 20.001 } \\
\text { a 50.000 }\end{array}$ & $\begin{array}{c}\text { De 50.001 } \\
\text { a 100.000 }\end{array}$ & $\begin{array}{c}\text { Más } \\
\mathbf{1 0 0 . 0 0 1}\end{array}$ \\
\hline Soria & 1 & 0 & 1 & 0 & 0 \\
\hline Valladolid & 9 & 0 & 3 & 0 & 1 \\
\hline Zamora & 1 & 1 & 0 & 1 & 0 \\
\hline Total Castilla y León & 37 & 7 & 7 & 5 & 4 \\
\hline
\end{tabular}

Fuente: INE, Estadística del Padrón Continuo a 1 de enero de 2019.

\section{LAS REFORMAS EN CASTILLA Y LEÓN: TEJER Y DESTEJER}

\subsection{Las competencias sobre la planta local}

La situación actual de las entidades locales, a las que se refiere el vigente texto constitucional, refleja la existencia de 8.131 municipios en nuestro país y una diversa tipología adicional de entidades locales, ora inframunicipales (entidades locales menores) ora supramunicipales (mancomunidades y comarcas), que elevan esta cantidad en las siguientes cifras: Entidades de Ámbito Territorial Inferior al Municipio (EATIM) ${ }^{7}$ : 3.691, Mancomunidades: 966, Comarcas: 82 y Áreas metropolitanas: 3 (Registro de entidades locales del Ministerio de Hacienda y Administraciones Públicas, 2019).

El sumatorio final asciende a 12.873 entidades. A este número se deberá añadir el de las provincias, que suman 50 , y las islas, que se eleva a 11 .

Resulta curioso, y realmente preocupante en términos de eficiencia y sostenibilidad, que la Constitución gaditana de 1812 exigiera más de 1.000 habitantes para constituir un municipio, y actualmente no se exija cifra alguna para el mantenimiento como entidad local de las ya existentes con independencia de su población y sostenibilidad. Así, mientras parte de la doctrina no apoya la supresión de municipios (Quintana, 2014: 35), por entender que esta política no sería positiva en términos de ahorro y eficiencia; otra parte, por el contrario, apoyan medidas de fusión obligatoria de municipios para conseguir la existencia de una planta municipal viable y sostenible (Cosculluela, 2013: 11, Martínez, 2006: 67).

Todo ello, conduce a la existencia actual de casi 5.000 municipios con una población que no supere esta cantidad de población de 1.000 habitantes.

En una dimensión jurídico-competencial, la determinación del concepto y la estructura de la planta municipal es competencia del legislador estatal, pues:

corresponde al Estado optar, de entre los posibles, por un determinado modelo municipal. Así, el Estado podía haberse inclinado por un modelo minifundista, basado en la existencia de núcleos de población sin exigencia alguna de un mínimo territorial, o por un modelo basado en mayores exigencias de población y territorio, si es que lo hubiera considerado necesario para garantizar la viabilidad del ejercicio de las competencias que se atribuyen a los municipios y con ello su autonomía, o por una combinación de ambos en función de la realidad existente o, finalmente, por un modelo que dejase un amplio margen de decisión a las Comunidades Autónomas para configurar el elemento territorial de los municipios (STC 103/2013, de 25 de abril, FJ. 5).

Llegando la jurisprudencia del Tribunal Constitucional a afirmar que es una competencia del legislador estatal la posible fijación de mínimos poblacionales en los municipios (STC 41/2016, de 3 de marzo, FJ. 6).

Esta competencia no ha sido ejercida por el legislador postconstitucional estatal hasta la Ley 27/2013, de 27 de diciembre, de racionalización y sostenibilidad de la Administración local (LRSAL), la cual establece en la nueva redacción del artículo 13.2 LRBRL un mínimo poblacional de 5.000 habitantes, así como la necesidad de "que los municipios resultantes sean financieramente sostenibles», pero estas condiciones legales operan exclusivamente para la creación de nuevos municipios (Pons, 2016: 106).

7 En cuanto a su denominación, puede apelarse a ellas como entidades de ámbito territorial inferior al municipio (EATIM) o, el más tradicional, de entidades locales menores (ELM), que es como se las denomina en la legislación local de Castilla y León. 
Y dentro de esta competencia estatal no se incluye la de fusionar los municipios (STC 214/1989, de 21 de diciembre, FJ. 9), aunque sí puede este ejercer una acción de fomento a fin de favorecer las fusiones de municipios, buscando con ello una mayor capacidad de gestión en las entidades locales (cit., FJ. 9). Pues la competencia sobre alteraciones de los términos municipales es una competencia que el artículo 148.1.2. ${ }^{\circ}$ CE permite ser asumida por las Comunidades Autónomas (Carbonell, 2013: 28), lo cual ha sido realizado masivamente tras la aprobación de los correspondientes Estatutos de Autonomía; no obstante ello, pese a que resulta una competencia exclusiva de las Comunidades Autónomas, también hay que concluir que no ha sido ejercida por estas para la reformulación de la planta local, hasta el punto que las Comunidades Autónomas han tenido en esta materia una oportunidad inédita en la historia del régimen local español.

En lo que se refiere a las entidades locales menores, al involucrar intereses municipales, estas cobran relevancia bajo la óptica de la garantía constitucional de la autonomía local (artículo $137 \mathrm{CE}$ ). Si bien la constitución y determinación de su régimen jurídico, de carácter puramente contingente o voluntario, depende de la normativa autonómica, «ello no quiere decir que ni las entidades municipales, ni tampoco el Estado, queden radicalmente al margen de ese proceso de constitución» (STC 214/1989, cit., FJ. 15. a).

Se puede seguir cuestionando la existencia de una planta local tan numerosa, y de la que se predica de forma indiscriminada su autonomía local (Sosa, 1989: 29, Martín y Sosa, 1999: 314), y sin llegar a soluciones tan drásticas como la disolución de los municipios más pequeños, tampoco parece que estén teniendo gran fortuna los instrumentos legales de las fusiones voluntarias de municipios (Carbonell, 2018: 13, Calonge, 2015: 47), por lo que parece necesario que se debiera establecer en la propia Carta Magna la garantía de la sostenibilidad de los municipios como requisito para su reconocimiento legal, operando tanto para los ya existentes como para los de nueva creación.

Vista la situación competencial en el ámbito de la determinación de la planta local, la Comunidad de Castilla y León ha optado por una política contraria a la supresión de las EATIM y tampoco se ha realizado ninguna alteración municipal para fusionar municipios, todo lo cual ha abocado a una actuación estratégica en materia de ordenación del territorio que, manteniendo la actual planta local, permita la mejora de la eficiencia de la prestación de los servicios públicos locales.

El Estatuto de Autonomía de Castilla y León (aprobado el texto vigente por Ley Orgánica 14/2007, de 30 de noviembre, BOE 1 de diciembre, EACyL), establece como competencia exclusiva, artículo 70.1.4, «la organización territorial de la Comunidad. Relaciones entre las instituciones de la Comunidad y los entes locales y regulación de los entes locales creados por la Comunidad, en los términos previstos en el presente Estatuto», y como competencia compartida, de desarrollo normativo y ejecución, la competencia sobre régimen local, artículo 71.1.1.

Debe apuntarse, como evidencia de la situación de la despoblación en Castilla y León, que este EACYL proclama, como uno de sus principios rectores de las políticas públicas: la lucha contra la despoblación, articulando las medidas de carácter institucional, económico, industrial y social que sean necesarias para fijar, integrar, incrementar y atraer población, artículo 16.

Este EACyL enumera las diversas entidades locales: municipios, provincias y demás entidades locales que con tal carácter puedan crearse conforme a la ley, artículo 43.1, y que en preceptos siguientes describe con mayor detalle, al referirse expresamente al municipio, a la comarca y a la provincia en los artículos 44,46 y 47.

La regulación jurídica de este Estatuto de Autonomía, en este ámbito de la organización territorial local, se encuentra contenida en su Título III, el cual comienza con una declaración de principios del siguiente tenor: «las entidades locales de Castilla y León se regirán por los principios de autonomía, suficiencia financiera, competencia, coordinación, cooperación, responsabilidad, subsidiariedad y lealtad institucional» (artículo 43.2).

Esta declaración de principios debe completarse con el contenido del artículo 48, precepto que establece que las relaciones entre la Comunidad Autónoma y las entidades locales se ajustarán a los principios de:

lealtad institucional, respeto a los ámbitos competenciales respectivos, coordinación, cooperación, información mutua, subsidiariedad, solidaridad interterritorial y ponderación de los intereses públicos afectados, cualquiera que sea la Administración que los tenga a su cargo.

Y dentro del ámbito subjetivo de aplicación de este artículo 43.2 del EACyL, se está refiriendo tanto a las entidades locales garantizadas constitucionalmente (municipios y provincias), como a las demás entidades locales que con tal carácter puedan crearse conforme a la ley.

Esta cláusula normativa supone un importante efecto expansivo, pues hace referencia a un conjunto de diversas entidades, como pueden las comarcas, las mancomunidades y las EATIM, y resulta de espe- 
cial importancia por cuanto dota a la diversa tipología de entidades locales de los principios de autonomía, suficiencia financiera, competencia, coordinación, cooperación, responsabilidad, subsidiariedad y lealtad institucional, artículo 43.2.

En una suerte de política de café para todos, se iguala por arriba la situación estatutaria de la totalidad de las entidades locales existentes en la Comunidad Autónoma de Castilla y León. Lo cual supone una regulación normativa ciertamente significativa, en relación con el texto constitucional, con la normativa estatal sobre régimen local y con la redacción anterior de este Estatuto de Autonomía ${ }^{8}$, cual es la de extender el principio constitucional de autonomía a la totalidad de las entidades locales, cuando el resto de las normas ya citadas, y en particular el texto constitucional, solo la extiende a municipios, provincias e islas (artículos 137,140 y 141 de la CE).

Para conocer, e identificar, la diversa tipología de las entidades locales existentes en nuestro Derecho, la normativa estatal contenida en la LRBRL establece que serán entidades locales territoriales «el municipio, la provincia (...)», y gozarán asimismo de esta condición «las comarcas u otras entidades que agrupen a varios municipios (...). Las mancomunidades de municipios» (artículo 3 LRBRL).

Y se debe destacar que, con la reforma de la LRSAL se ha suprimido cualquier referencia en este precepto a las EATIM, y que hasta esta reforma del año 2013, eran consideradas como una variedad de la amplia tipología de entidades locales. No obstante ello, debe precisarse que esta regulación jurídica solo resulta aplicable a las EATIM que se constituyan ex novo, pues la disposición transitoria $4 .^{a}$ de la LRSAL establece expresamente que: «las entidades de ámbito territorial inferior al Municipio existentes en el momento de la entrada en vigor de la presente Ley mantendrán su personalidad jurídica y la condición de Entidad Local».

En breve, las EATIM existentes anteriores a la entrada en vigor de esta ley, la cual se produjo en fecha 31 de diciembre de 2013, tendrán la consideración de entidades locales, y gozarán de personalidad jurídica, mientras que las de nueva creación ${ }^{9}$, ni serán entidades locales, ni tendrán personalidad jurídica, pues el nuevo artículo 24 bis LRBRL establece, en su apartado $1 .^{\circ}$, que las leyes de las Comunidades Autónomas sobre régimen local regularán los entes de ámbito territorial inferior al Municipio, que carecerán de personalidad jurídica, como forma de organización desconcentrada del mismo para la administración de núcleos de población separados, bajo su denominación tradicional de caseríos, parroquias, aldeas, barrios, anteiglesias, concejos, pedanías, lugares anejos y otros análogos, o aquella que establezcan las leyes.

En el ámbito autonómico de Castilla y León, la regulación de las entidades locales se encuentra contenida en la Ley 1/1998, de 4 de junio, de Régimen local de Castilla y León (LRLCYL), la cual parte de una definición del Municipio, como:

«entidad local básica de la organización territorial de la Comunidad de Castilla y León, goza de personalidad jurídica propia y plena capacidad para el cumplimiento de sus fines, gestiona con autonomía sus propios intereses y tiene como elementos sustanciales el territorio, la población y la organización» (artículo 2.1),

y de una garantía legal a su suficiencia financiera, al afirmarse en su apartado segundo de este precepto que la Junta de Castilla y León garantizará que los municipios dispongan de los medios adecuados y suficientes para el cumplimiento eficaz de sus fines.

En este ámbito de la capacidad económica municipal, el artículo $13 \mathrm{c}$ ), regula como uno de los supuestos para la supresión de los municipios, para incorporarse a otro, el siguiente: insuficiencia de medios para prestar los servicios mínimos exigidos por la Ley; completando la letra d), el siguiente otro supuesto legal: existencia de condiciones económicas, administrativas o de cualquier otro carácter que pudieran hacerla necesaria o conveniente.

Y esta Ley contiene un listado de medidas normativas para fomentar las fusiones e incorporaciones de los municipios, tratando de alcanzar núcleos de población de, al menos, 1.000 habitantes, al disponer el artículo 18 las siguientes medidas:

8 Pues tanto en la redacción realizada por la Ley Orgánica 4/1983, de 25 de febrero, como en la modificación introducida por la Ley Orgánica 4/1999, de 8 de enero, la autonomía local solo se refería a los municipios y provincias, artículos 19 y 25 del EACYL, respectivamente.

9 Salvo aquellas reguladas por la disposición transitoria quinta de la LRSAL, en la que se establece que, «el núcleo de población que antes del 1 de enero de 2013 hubiera iniciado el procedimiento para su constitución como entidad de ámbito territorial inferior al Municipio, una vez que se constituya, lo hará con personalidad jurídica propia y con la condición de entidad local y se regirá por lo dispuesto en la legislación autonómica correspondiente». 
- Creación de un fondo y concesión de ayudas para la mejor prestación de los servicios por el municipio resultante.

- Preferencia en las líneas de ayudas generales a los municipios que opten por esta opción.

- Igualmente, requiere a las Diputaciones provinciales que opte por priorizar en sus líneas de subvenciones a estos municipios.

- Fomento de los convenios para la coordinación con las posibles medidas que se adopten en este mismo sentido por el Estado.

La tacha que se puede hacer a esta previsión legislativa reguladora de las fusiones voluntarias de municipios se centra en su evidente ineficacia, pues han sido muy pocos los municipios que han optado por estas medidas de fusión voluntaria en toda España y en Castilla y León ${ }^{10}$.

Esta LRLCYL trata de perfilar un régimen jurídico propio para los municipios de menos de 5.000 habitantes, artículo 77, para los cuales la Junta de Castilla y León aprobaría un reglamento orgánico, que se aplicaría supletoriamente en el supuesto de que estos no lo hayan aprobado, y así tratar de adaptar la organización complementaria y el funcionamiento responderán a los principios de sencillez, economía, eficacia y participación ciudadana. Igualmente, se posibilita que la Junta de Castilla y León establezca «modelos-tipo de actas, acuerdos, ordenanzas, plantillas y otros documentos municipales para facilitar una actuación administrativa unitaria y ágil». Desarrollo normativo que no se ha producido.

En lo que se refiere a la regulación jurídica de las EATIM en relación con su tipología, el artículo 49.2 las configura como una entidad local con «personalidad y capacidad jurídica plena para el ejercicio de sus competencias». En definitiva, no se afirma de forma expresa su configuración como entidad local territorial, aunque sí se deduce implícitamente a la vista del conjunto principios estatutarios derivados de su condición de entidades locales (Bello, 2015: 207).

Si bien en una primera valoración pudiera parecer positiva la ampliación realizada en el marco estatutario, no se puede obviar que esta actuación supone un incremento significativo de las cargas financieras en el ámbito de esta Comunidad Autónoma, pues supone garantizar la suficiencia financiera a todo tipo de entidades locales, y ello desde que estas existan legalmente.

No se puede obviar que esta Comunidad Autónoma debe garantizar esta suficiencia de recursos a las entidades locales, según establecen los artículos 53 y 55 EACyL, y ello con la finalidad última de «garantizar la igualdad en el acceso a los servicios públicos locales a todos los ciudadanos de la Comunidad» (artículo 53), lo que supone aceptar el formidable reto de garantizar la suficiencia financiera de más de 4.700 entidades jurídico-públicas locales diversas, de las cuales 2.220 son EATIM, lo cual supone una auténtica "cuadratura del círculo».

\subsection{La reforma local desde el paradigma de la ordenación del territorio}

Para abordar una necesaria actuación de racionalización de la planta local en Castilla y León, se ha empleado la competencia contenida en el vigente Estatuto de Castilla y León sobre ordenación del territorio, artículo 70.1, cuando establece que «la Comunidad de Castilla y León tiene competencia exclusiva en las siguientes materias: (...). $6 .{ }^{\circ}$ Ordenación del territorio, urbanismo y vivienda».

Esta competencia autonómica ha sido entendida por el Tribunal Constitucional en el sentido de que, tiene por objeto la actividad consistente en la delimitación de los diversos usos a que pueda destinarse al suelo o espacio físico territorial, añadiendo que:

el núcleo fundamental de esta materia competencial está constituido por un conjunto de actuaciones públicas de contenido planificador cuyo objeto consiste en la fijación de los usos del suelo y el equilibrio entre las distintas partes del territorio mismo. (STC 36/1994, de 10 de febrero, FJ. 3).

Y en ejercicio de esta competencia autonómica, se aprobó la Ley 10/1998, de 5 de diciembre, de Ordenación del Territorio de la Comunidad de Castilla y León, que tiene como principios los de coordinación y

10 Desde la aprobación de la LRSAL, se ha producido una única fusión de municipios en toda España, por la cual se ha creado un nuevo municipio, Cercedo-Cotobade, en la provincia de Pontevedra, BOE de 27 de enero de 2017. Anteriormente, en esa misma Comunidad Autónoma, se había producido la creación por fusión del municipio de Oza-Cesuras, en la provincia de A Coruña, BOE de 18 de junio de 2013. Y habría de remontarse al año 1981 para encontrar la anterior fusión de municipios, esta vez en Castilla y León, con la creación del municipio de Valle de Losa, por la fusión de los municipios de Junta de Río de Losa y Junta de San Martín de Losa, así como de varias EATIM, en la provincia de Burgos, BOE de 9 de marzo de 1981. 
cooperación administrativa, para asegurar la coherencia en la actuación de las Administraciones públicas y la participación social, artículo 2.1; y como objetivos: la promoción de su desarrollo equilibrado y sostenible, el aumento de la cohesión económica y social y la mejora de la calidad de vida de sus habitantes, así como la gestión responsable de los recursos naturales y la protección del medio ambiente y del patrimonio cultural, artículo 2.2.

Objetivos que luego quedan definidos legalmente, con más precisión en los siguientes términos, entre otros: «a) Definir un modelo territorial para Castilla y León, capaz de favorecer la articulación e integración de su territorio y su conexión con el exterior de la Comunidad, con especial atención a los núcleos que por sus características y posibilidades puedan constituirse en centros de desarrollo comarcal (...)».

Pues bien, en ejercicio de esta misma competencia autonómica, se ha aprobado la ley autonómica 7/2013, de 27 de septiembre, de ordenación, servicios y gobierno de la Comunidad de Castilla y León (LORSERGO) ${ }^{11}$, la cual pretende:

a) Delimitar los espacios funcionales para efectuar la ordenación territorial, en el ejercicio de la competencia exclusiva de la Comunidad Autónoma. b) Planificar y programar los servicios autonómicos, de acuerdo con el modelo territorial, en el ejercicio de la competencia exclusiva de la Comunidad Autónoma. c) Potenciar fórmulas de gobierno y administración local más eficientes, especialmente las de carácter asociativo voluntario, así como fomentar la solidaridad de la comunidad municipal, en el ejercicio de las competencias exclusivas y de desarrollo normativo y de ejecución de la Comunidad Autónoma (artículo 1).

Pese a que la competencia de ordenación del territorio solo es una de las que se ejercitan en esta norma legal, resulta evidente que es esta la que obliga al resto a su alineamiento, pues también se ejercen las competencias estatutarias sobre la "estructura y organización de la Administración de la Comunidad», artículo 70.1, apartado $2 .^{\circ}$ EACYL y sobre la «organización territorial de la Comunidad. Relaciones entre las instituciones de la Comunidad y los entes locales y regulación de los entes locales creados por la Comunidad, en los términos previstos en el presente Estatuto» (artículo 70.1, apartado $4 .^{\circ} \mathrm{EACYL}$ ).

Entrando en el contenido de este movimiento reformador, la LORSERGO pretende reorganizar las actuales mancomunidades, creando las mancomunidades de interés general (MIG), con la finalidad de que estas puedan gestionar con eficiencia los recursos municipales a través de la generación de economías de escala, apartado II de la Exposición de Motivos. Sin que la creación de estas MIG suponga un nuevo escalón local, pues se pretende la sustitución por estas de las actuales mancomunidades, lo que lleva implícito un obligatorio, que no voluntario, ajuste de la planta local.

Dentro de esta tipología presentan una especial importancia las de carácter rural. Estas mancomunidades de interés general tienen la misma naturaleza jurídica que las mancomunidades tradicionales: entes locales de base asociativa y voluntaria.

En el caso de las rurales, el artículo 37.1 establece que esta tipología de MIG «es la surgida de la asociación voluntaria entre municipios con población inferior o igual a 20.000 habitantes, excepto en aquellos

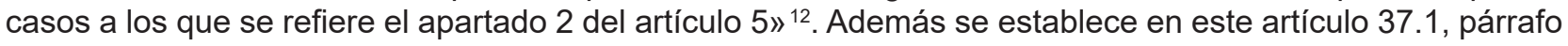
segundo, que «el ámbito territorial de esta mancomunidad deberá coincidir sustancialmente con la unidad básica de ordenación y servicios del territorio rural $(\ldots) »^{13}$, lo cual deja limitado el principio de voluntariedad asociativa, al establecerse de forma imperativa su ámbito territorial.

11 Norma legal que ha servido de precursora de un conjunto de disposiciones legales y reglamentarias que han compuesto un amplio subsistema en relación con la ordenación del territorio en Castilla y León. De esta forma, se puede citar la Ley 9/2014, de 27 de noviembre, por la que se declaran las áreas funcionales estables en Castilla y León y se modifica la Ley $7 / 2013$, de 27 de septiembre, de Ordenación, Servicios y Gobierno del Territorio de la Comunidad de Castilla y León; el Decreto-Ley 1/2018, de 24 de mayo, por el que se modifica la Ley 7/2013, de 27 de septiembre, de ordenación, servicios y gobierno del territorio de la Comunidad de Castilla y León. También el Decreto-Ley 2/2018, de 23 de agosto, por el que se modifica la Ley 7/2013, de 27 de septiembre, de ordenación, servicios y gobierno del territorio de la Comunidad de Castilla y León. Y en el ámbito reglamentario, se puede citar el Decreto 30/2015, de 30 de abril, por el que se aprueba el Reglamento de Organización y Funcionamiento de las Mancomunidades de interés general. No obstante esta pléyade de normas jurídicas, a fecha actual la ordenación del territorio contemplada en esta normativa jurídica no ha tenido una plasmación real.

12 Precepto que establece la posibilidad de existir UBOST urbanas para «aquellos municipios que, contando con una población aproximada de 19.000 habitantes disten más de 50 kilómetros de una unidad básica de ordenación y servicios urbana, cuando se integren en una de las áreas funciones estables previstas en el artículo $8 »$.

13 Resulta muy cuestionable la ligereza en la redacción de la disposición final primera de la Ley 9/2014, en la cual se establece, apartado 4, lo siguiente: «se modifica el apartado 1 del artículo 37, que pasa a tener la siguiente redacción (...)», cuando debiera haber expresado que la reforma se refiere al párrafo $1 .^{\circ}$ de este apartado, no a los dos párrafos siguientes. 
Su ámbito competencial, según el artículo 41.1, incluirá una cartera común y homogénea de competencias y funciones de entre las materias previstas en la normativa de régimen local, que serán determinadas reglamentariamente, artículo 41.2. Lo cual también supone el establecimiento de otra condición imperativa para estas MIG.

$Y$ además, recientemente, se han equiparado a las mancomunidades de interés general rurales, como instrumentos necesarios para esta ordenación del territorio, a la Comarca de El Bierzo y a Las Comunidades de Villa y Tierra, Comunidades de Tierra, Asocios y otras entidades asociativas tradicionales existentes en Castilla y León ${ }^{14}$.

Dicho de otra forma, bajo la personificación jurídica de entidades asociativas locales ya existentes, se pretende aplicar una actividad planificadora sobre los municipios de menos de 20.000 habitantes, con la excepción contenida en el artículo 5.2 LORSERGO.

Estableciendo el artículo 42.1 como MIG urbana: «la surgida de la asociación voluntaria entre los municipios con población superior a 20.000 habitantes y los municipios de su entorno o alfoz que cumplan los requisitos previstos en esta ley». Para identificar a estos municipios se utiliza el instrumento legal del área funcional, de forma que en cada área funcional estable solo podrá declararse una mancomunidad como de interés general urbana, a la que podrán asociarse todos o algunos de los municipios pertenecientes a dicha área, párrafo segundo de este precepto.

Pese a que esta regulación data del año 2013, a fecha actual, aún no se han podido constituir este tipo de mancomunidades de interés regional, por cuanto no se ha procedido a la aprobación del mapa de ordenación territorial, definido en el artículo 3.2 de la LORSERGO, y ello dado que este mapa debe ser aprobado «mediante una norma con fuerza de ley, y que precisará el apoyo de dos tercios de las Cortes de Castilla y León» (artículo 6.1).

Y este proyecto de ley no ha tenido la necesaria mayoría parlamentaria, por lo que toda la estrategia de ordenación territorial está parada, «en el ovillo de Penélope», desde hace más de seis años.

El proyecto de esta ley autonómica tiene como denominación: «PL 8/9 por la que se aprueba el mapa de unidades básicas de ordenación y servicios del territorio de Castilla y León, y se modifican la Ley 7/2013, de 27 de septiembre, de Ordenación, Servicios y Gobierno del Territorio de la Comunidad de Castilla y León, y la Ley 9/2014, de 27 de noviembre, por la que se declaran las áreas funcionales estables de Castilla y León».

$Y$ es de tal envergadura el bloqueo parlamentario que, en el procedimiento seguido ante las Cortes de Castilla y León, el último trámite realizado se remonta al día 15 de septiembre de 2017, en el cual se acordó por la Mesa de estas Cortes conceder una nueva prórroga del plazo de presentación de enmiendas al Proyecto de Ley por la que se aprueba el mapa de unidades básicas de ordenación y servicios del territorio de Castilla y León, y se modifican la Ley 7/2013, de 27 de septiembre, de Ordenación, Servicios y Gobierno del Territorio de la Comunidad de Castilla y León, y la Ley 9/2014, de 27 de noviembre, por la que se declaran las áreas funcionales estables de Castilla y León, hasta las 14:00 horas del día 10 de octubre de $2017^{15}$. Hay que esperar que en esta nueva legislatura del parlamento autonómico se desbloquee esta situación. En este sentido se ha aprobado un Anteproyecto de Ley por el que se modifica la Ley $7 / 2013$, de 27 de septiembre, de Ordenación, Servicios y Gobierno del Territorio de Castilla y León que pretende simplificar la puesta en marcha de la ordenación del territorio en Castilla y León, al suprimir la mayoría reforzada antes aludida y sustituir a las UBOST por Áreas funcionales, rurales y urbanas.

Pese a la paralización de la aprobación del mapa de ordenación del territorio, resulta necesario que se haga un breve estudio de la situación jurídica de la actividad reformadora de las entidades locales en Castilla y León, contenida en las denominadas «unidades básicas de ordenación y servicios del territorio de Castilla y León» (UBOST). Pues, entre otros motivos, porque el legislador autonómico pretende una equiparación territorial de las MIG y las UBOST.

14 El Decreto-Ley 1/2018 ya citado, además, pretende utilizar la figura de las comarcas para esta ordenación del territorio, al establecer que la única comarca existente, la del Bierzo, «tendrá derecho a un tratamiento similar al previsto para las mancomunidades de interés general en las ayudas de la Administración de la Comunidad de Castilla y León, siempre que la mayoría de los municipios que lo componen manifiesten su voluntad de delegar en la misma competencias y funciones municipales» (artículo único, que modifica la disposición adicional $2{ }^{\circ}$ LORSERGO). Y esa es la misma finalidad que pretende el Decreto-Ley 2/2018, antes citado, al incorporar a este movimiento de ordenación del territorio a «Las Comunidades de Villa y Tierra, Comunidades de Tierra, Asocios y otras entidades asociativas tradicionales que cumplan lo dispuesto en el artículo 37.5 de esta ley, tendrán derecho a las ayudas de la Administración de la Comunidad de Castilla y León con el mismo tratamiento que se otorgue a las mancomunidades de interés general» (artículo único).

15 BOCCYL núm. 314, de fecha 19 de septiembre de 2017, pág. 39.721. Siendo ésta la quinta prórroga concedida por la Mesa de las Cortes en la tramitación de este Proyecto de Ley. 
Estas UBOST son definidas legalmente como aquellos espacios funcionales delimitados geográficamente, que constituyen la referencia espacial y el parámetro básico para el desarrollo de la ordenación del territorio de Castilla y León, artículo 3.1 LORSERGO.

El primer problema de las UBOST es su indefinición legal, pues el legislador utiliza la expresión normativa "espacios funcionales delimitados geográficamente», sin determinar expresamente si ostentan la condición de órganos administrativos o si ostentan personalidad jurídica alguna, o si integran potestades públicas, y ello pese a la importancia que se pretende otorgarlas: constituyen la referencia espacial y el parámetro básico para el desarrollo de la ordenación del territorio de Castilla y León, artículo 3.1.

De la lectura del resto de preceptos normativos se evidencia que el legislador autonómico pretende utilizar las entidades territoriales ya existentes, municipios, mancomunidades, comarcas, y otras entidades asociativas tradicionales, para que actúen sus competencias en el espacio determinado por las distintas UBOST: artículo 37.1 para las MIG rurales y artículo 42.1 para las MIG urbanas.

Además, las UBOST representan la unidad de métrica de la ordenación territorial en Castilla y León, pues no de otra forma puede entenderse el contenido del artículo 10.1 cuando establece que: la Administración de la Comunidad de Castilla y León utilizará como base territorial para la planificación y programación de sus servicios urbanos y rurales, cuando el ámbito funcional deba ser inferior al de la provincia, la unidad básica de ordenación y servicios del territorio.

En definitiva, esta previsión legislativa se refiere a las UBOST, como el territorio sobre el que operará la actividad planificadora y programadora de los servicios autonómicos sobre el territorio de Castilla y León. Pero si ello es así, queda pendiente en esa reforma la prestación de los servicios autonómicos por la propia Administración periférica de la Junta de Castilla y León.

Por lo que en conclusión, las UBOST son fundamentalmente una nueva división del territorio de Castilla y León, para la prestación de las competencias autonómicas y locales.

De esta forma, se pretende una reforma territorial sin proceder a la supresión de los municipios, ni de las EATIM, pues no se plantea la desaparición de ninguna entidad local, sino que se basa en la asociación de municipios en las MIG, rurales y urbanas. Y es que, subyace a esta profunda reforma local, otra que se realizó anteriormente en materia de prestación de servicios sanitarios, con la creación de las Zonas Básicas de Salud, pero la gran diferencia entre ambas reformas se centra en la tipología de las actividades prestadas, pues estas últimas sirvieron para la fijación del ámbito de prestación únicamente del servicio público sanitario.

Estableciendo el artículo 11 LORSERGO que, en los servicios esenciales que se prestan por la Junta de Castilla y León, se atemperarán a las siguientes reglas:

1. ${ }^{a}$ Para la prestación de la asistencia sanitaria, cada zona básica de salud deberá coincidir con una UBOST.

2. ${ }^{a}$ Para la prestación de los servicios sociales básicos, cada zona de acción social deberá comprender un mínimo de una UBOST y un máximo de tres.

3. ${ }^{a}$ Para la prestación de la educación obligatoria, cada zona educativa deberá comprender un mínimo de una UBOST y un máximo de cinco.

4. ${ }^{\text {a }}$ Para la prestación de los servicios de salud pública, cada demarcación de salud pública deberá comprender un mínimo de dos UBOST y un máximo de seis.

Además, el propio legislador pretende que estas UBOST sean también el ámbito territorial de la prestación de los servicios locales, pues en el ámbito de las rurales establece expresamente que estas coincidan con las mancomunidades de interés general rural, artículo 37.1, las cuales deberán prestar una cartera común y homogénea de materias, competencias y funciones propias de las mancomunidades de interés general rurales ${ }^{16}$, artículo 37.4 .

Y en el ámbito urbano, referido generalmente a los municipios de más de 20.000 habitantes, el artículo 42.3 establece que:

las mancomunidades de interés general urbanas incluirán en sus estatutos las competencias y funciones que se acuerden, de entre las materias previstas en la normativa de régimen local.

16 Añadiendo el artículo 41.3 que «no se podrá realizar ninguna actividad administrativa municipal que directa o indirectamente suponga el ejercicio de las competencias mancomunadas». 
Especialmente, podrán incluir aquellas que se refieran al abastecimiento de agua, al saneamiento y depuración de aguas residuales, al transporte público intermunicipal de viajeros, y a la seguridad ciudadana, protección civil y extinción de incendios, u otras que se concreten reglamentariamente.

El proyecto de división del territorio de Castilla y León en UBOST contiene la creación de 177 UBOST rurales y 16 UBOST urbanas, lo que conllevaría que la actual planta local en Castilla y León sería sustituida de facto y como entes prestadores de una parte importante de los servicios públicos de competencia local, por 193 entidades. La rotundidad y contundencia de esta actividad de planificación es evidente, pues en la actualidad la prestación de estos servicios es realizada por más de 4.700 entidades locales.

Por ello no puede sorprender las reticencias mostradas por Alcaldes, Presidentes de Diputación y el principal partido de la oposición en el sentido de que esta actuación pueda menoscabar la autonomía local, en un sentido financiero, y pueda también perjudicar la calidad de la prestación de los servicios locales.

Por último, se debe señalar que la LORSERGO también constituye, como un escalón por encima de las UBOST, las áreas funcionales como «espacios geográficos delimitados para el desarrollo de la ordenación del territorio de Castilla y León y la aplicación de instrumentos y herramientas de planificación y gestión», artículo 7.

Estas áreas funcionales, en el diseño de la Ley, son de dos tipos:

a) Las áreas funcionales estables, formadas por las UBOST urbanas y los municipios de su entorno o alfoz con los que mantienen relaciones funcionales que precisan una planificación conjunta, artículo 8.1; municipios de su entorno que tienen que ser colindantes o que no disten más de 15 kilómetros del municipio de mayor población, artículo 8.2. En total se han sido declaradas 14 áreas funcionales, sin que ello haya supuesto ninguna modificación en la prestación de las competencias y servicios públicos de los municipios integrados.

b) Las áreas funcionales estratégicas, artículo 9.1 LORSERGO, que estarán «integradas por una unidad básica de ordenación y servicios del territorio o por varias contiguas, para el impulso de programas de desarrollo en aquellas zonas de menor dinamismo económico y demográfico, o afectadas por circunstancias extraordinarias». Estando estas áreas funcionales limitadas en su constitución por la necesaria aprobación del mapa de las UBOST, artículo 9.2.

\section{PROPUESTAS DE SOLUCIÓN}

Para poder dar curso a la solución de un problema encastrado en la vida política y social de Castilla y León desde su creación en los años ochenta, y con anterioridad en el espacio geográfico que hoy abarca esta región, nosotros nos centraremos en desarrollar tres propuestas por entender que pueden construir un entramado organizativo e instrumental que sirvan de guía para el resto; pues se puede generar un listado inagotable de medidas a implantar, como sucede actualmente en la vigente "Agenda para la población de Castilla y León 2010-2020" que cuenta con 174 medidas.

\subsection{Reforma de la planta local o mantenimiento de la actual estructura territorial en Castilla y León: el paradigma de las MIG}

Desde nuestro punto de vista resulta prioritario el ejercicio efectivo de la competencia de ordenación del territorio para el establecimiento de la estructura territorial que permita la implantación del resto de medidas para luchar contra la despoblación en Castilla y León.

En este sentido resulta sorprendente que la citada Agenda para población se formule al final de esta, como medida número 166 de las 173 que se relacionan, la siguiente:

desarrollo de la Ley 7/2013, de 27 de septiembre, de Ordenación, Servicios y Gobierno del Territorio de la Comunidad de Castilla y León, y, en particular: a. Definición del mapa de unidades básicas de ordenación y servicios del territorio. b. Delimitación de las áreas funcionales estables y estratégicas. c. Promoción de la constitución de mancomunidades de interés general", cuando debiera ser de las primeras dado su carácter arquitectural del sistema organizativo de la prestación de los servicios públicos locales y autonómicos. 
La primera propuesta para realizar es la implantación real y efectiva de las UBOST, las MIG, rurales y urbanas, y las áreas funcionales.

Resulta evidente que no puede sostenerse un mapa local en esta Comunidad Autónoma con más de 4.700 entidades locales como prestadoras de servicios a los ciudadanos, por lo que descartada la posible fusión obligatoria de municipios, resulta necesaria la implantación de prestación de servicios públicos a través de entidades supramunicipales, como son las MIG; las cuales sin suprimir entidades locales, van a convertirse en las entidades prestadoras de las competencias municipales.

No parece una fórmula jurídica inapropiada pues consigue aunar la necesidad de racionalizar los limitados recursos públicos sin llegar a soluciones extremas como podrían ser las de la fusión obligatoria de municipios.

El gran problema de la política de ordenación del territorio en Castilla y León ha sido la de su implantación real, frenada por la ausencia de la mayoría política necesaria en el parlamento autonómico de dos tercios, según establece el artículo 6.1 de la LORSERGO.

Ante esta situación parlamentaria, sólo cabe dos soluciones; alcanzar un gran pacto político para obtener esta mayoría parlamentaria o proceder a modificar la LORSERGO para modificar este quorum reforzado que está bloqueando la necesaria labor de ordenación del territorio. Cualquiera de ellas deberá ser realizada en un breve lapso temporal; la urgencia y gravedad de la patología que supone la despoblación para Castilla y León obliga a una intervención urgente.

Otro gran problema irresuelto en esta labor reformadora es la ausencia de su cuantificación económica, por lo que debe resultar una prioridad política su establecimiento, así como la posterior dotación presupuestaria.

Además, y dada la actual distribución competencial autonómica, no parece adecuado que la competencia «de impulso y coordinación de la Agenda para la población» se encuentre sita en la Viceconsejería de Empleo y Diálogo Social, artículo 4 del Decreto 3/2019, de 24 de julio, del Presidente de la Junta de Castilla y León, por el que se crean y regulan las viceconsejerías; es decir, dentro de la Consejería de Empleo e Industria. Y la política de ordenación del territorio, que debe sustentar las líneas de actuación contra la despoblación, sea competencia de otra Consejería, la de Transparencia, Ordenación del Territorio y Acción Exterior, en concreto ubicada en la Dirección General de Ordenación del Territorio y Planificación, artículo 6 del Decreto 20/2019, de 1 de agosto, por el que se establece la estructura orgánica de la Consejería de Transparencia, Ordenación del Territorio y Acción Exterior ${ }^{17}$.

Y, por último, parece necesario la integración en el proceso de reforma al papel integrador y vertebrador de las pequeñas ciudades (> 5.000 habitantes) y las ciudades intermedias ( $>50.000$ habitantes). No parece suficiente la consideración de las MIG urbanas como motor de esta interacción de los municipios urbanos con los rurales, por cuanto sus características y necesidades pueden ser altamente heterogéneas e incompatibles.

\subsection{Reforma local y organización periférica de la Junta de Castilla y León}

Esta es una acción política ignota en esta región, pues desde su creación ha apostado por acciones de empoderamiento de los órganos centrales frente a los periféricos; situación que puede percibirse con el siguiente símil: «un Estado que pretendiese realizar a través de sus órganos centrales toda su actividad sería algo parecido a un monstruoso hombre con solo cabeza y carente de los restantes miembro» (Romano, 1961: 81).

Para evitar esta anomalía organizativa, deberá procederse a una reformulación de las relaciones con las Diputaciones provinciales y al fortalecimiento de las Delegaciones Territoriales de la Junta de Castilla y León.

Efectuando un breve análisis de la situación jurídica de la organización periférica de la Junta de Castilla y León se concluye que el órgano administrativo que culmina la Delegación provincial tiene una finalidad meramente institucional y representativa y con una limitada capacidad de colaboración y coo-

17 En concreto este precepto determina, entre otras, como competencia de este órgano administrativo las siguientes: «a) Las relativas a la ordenación del territorio en relación con la planificación de la gobernanza, administración y servicios del territorio. (...) c) La colaboración con las entidades locales y otros organismos y entes públicos locales y la coordinación técnica de éstos, así como el impulso de las mancomunidades de interés general, a los efectos de la ordenación del territorio. d) El estudio, propuesta y ejecución de medidas y actuaciones que en materia de gobernanza, administración y servicios en el territorio, han de servir de base para la planificación de la ordenación del territorio de la Comunidad. (...)». 
peración con el resto de las entidades territoriales intermedias, provincias, y con las propias entidades locales municipales.

De esta forma, en la Ley 3/2001, de 3 de julio, del Gobierno y de la Administración de la Comunidad de Castilla y León, se establece en su artículo 43.2 como competencias propias las siguientes:

a) Coordinar la acción política de la Junta de Castilla y León.

b) Coordinar e impulsar la actividad de la Administración General e Institucional de la Comunidad Autónoma en la provincia, así como los programas de actuación territoriales de la Delegación.

c) Proponer o informar a los órganos superiores y directivos centrales la resolución que estime procedente en los asuntos cuya tramitación esté encomendada a la Delegación Territorial.

d) Resolver los asuntos que le correspondan.

e) Desempeñar la jefatura de personal de la Delegación, sin perjuicio de las funciones que en este ámbito correspondan a otros órganos administrativos.

f) Velar por la correcta utilización de los medios materiales adscritos al funcionamiento de la Delegación Territorial y, en su caso, gestionarlos.

g) Las demás competencias que se le atribuyan, desconcentren o deleguen.

Norma legal que se ha desarrollado a través del vigente Decreto 25/2017, de 7 de septiembre, por el que se regula la estructura orgánica y las competencias de las Delegaciones Territoriales de la Junta de Castilla y León, que establece como competencias más significativas, en relación con las ya enumeradas en la Ley 3/2001, las siguientes:

- Presidir los órganos colegiados creados por la legislación sectorial en el ámbito provincial ${ }^{18}$.

- La dirección de las oficinas unificadas de apoyo empresarial.

- Impulsar la relación con el resto de las Administraciones Públicas de la provincia, así como ejercer las competencias compartidas con éstas.

Ejemplos de estas atribuciones y delegaciones, y su evidente limitación, se contienen en el Decreto $44 / 2018$, de 18 de octubre, $B O C Y L$ de fecha 22 de octubre, a través del cual se procede a atribuir en materia de minas e hidrocarburos, «el ejercicio de las competencias que las leyes y reglamentos en materia de minas e hidrocarburos atribuyen expresamente a los Delegados o Directores Provinciales de los Departamentos Ministeriales de la Administración General del Estado» (disposición adicional primera, apartado 2). En este mismo boletín oficial, el Decreto 45/2018, de 18 de octubre, procede a desconcentrar competencias en los Delegados Territoriales sobre las siguientes materias de sanidad: contratos de suministros, servicios y administrativos especiales, cuyo valor estimado sea inferior a 40.000 euros y contratos de obra, cuyo valor estimado sea inferior a 6.000 euros, previo informe favorable de la Secretaría General competente en materia de sanidad, artículo 2.4 .

Otro de los instrumentos jurídicos para la ampliación de las competencias de este órgano de la Administración periférica es, sin duda, la de la delegación de estas, pero la realidad que nos muestra el boletín oficial autonómico resume el ejercicio de esta delegación en aspectos residuales en términos administrativos.

En este sentido el $B O C Y L$ recoge resoluciones de delegación del ejercicio de competencias en materias tales como elaboración de las papeletas para las elecciones autonómicas a celebrar en el año 2015 en cada provincia, así como la gestión de los gastos y su ejecución presupuestaria, (BOCYL de fecha 19 de marzo de 2015); en materia de nombramiento de personal interino de los Servicios Territoriales de Sanidad y Bienestar Social (BOCYL de fecha 8 de octubre de 2013); el ejercicio de determinadas competencias en materia de autorizaciones sanitarias (BOCYL de fecha 24 de febrero de 2012); el ejercicio de las competencias en materia de distribución de los cupos de lobos correspondientes a cada comarca (BOCYL de fecha 4 de septiembre de 2009); la competencia para iniciar y resolver los procedimientos de incumplimiento y reintegro que se presenten al amparo de la Orden EYE/504/2009 de 5 de marzo, por la que se convocan subvenciones para el año 2009 dirigidas a fomentar la contratación indefinida de trabajadores con discapacidad, adaptación de sus puestos de trabajo o dotación de medios de protección personal y al tránsito del empleo protegido de los enclaves laborales al mercado ordinario de trabajo (BOCYL de fecha 8 de junio de 2009).

La mera lectura de esta relación de publicaciones oficiales pone en evidencia la ausencia de competencias ejecutivas importantes en este órgano periférico.

18 Sin duda es una competencia relativamente importante pues hace referencia a la Comisiones territoriales de Medio Ambiente y urbanismo, creadas al amparo del Decreto autonómico 24/2013, de 27 de junio. 


\subsection{Apuesta por las infraestructuras tecnológicas}

Acción extraordinaria y urgente para la implantación de las TIC, y en especial de Internet, en el ámbito urbano y rural de Castilla y León, con la implantación de las redes de comunicaciones rápidas y ultrarrápidas, la implantación de los servicios públicos en línea, con especial incidencia en la Administración electrónica y la promoción de las actividades empresariales de carácter tecnológico.

Esta línea de actuación deriva de la pérdida por la carrera tecnológica en esta Comunidad Autónoma, y con especial incidencia en los municipios de menor población.

Dado el elevado número de entidades locales existentes en Castilla y León, con una población tan escasa y envejecida, la/s TIC suponen una herramienta imprescindible para permitir la fijación de la población en estas localidades, con la utilización de las TIC para la prestación de servicios en línea; además, habilitará el posible incremento de la actividad económica en estos municipios y el incremento de población a otros colectivos que puedan poner en red su actividad económica o profesional.

Por ello, el futuro del acceso a Internet está centrado en el despliegue de redes fijas ultrarrápidas (que soporten velocidades superiores a los $100 \mathrm{Mbps}$ ), y el de las redes móviles de comunicaciones a través del Plan Nacional de 5G ("Consulta pública sobre el Programa de extensión de la Banda ancha de nueva generación (PEBA-NGA) en el período 2019-2021"), que persigue ahora la construcción de la Sociedad del Gigabit.

En el ámbito de este estudio, el hipotético acceso a las redes ultra rápidas situaría a las pequeñas poblaciones en igualdad de condiciones a las que disfrutan las áreas urbanas, democratizando el acceso a la información, facilitando a los ciudadanos la plena disponibilidad de los servicios de bienestar, como la sanidad, la educación o la cultura, y ofreciendo a las empresas el acceso a los mercados mundiales (Consulta, 2019: 3-4).

Y este no es un problema solo de España, en la UE también existe una importante brecha entra la población de las ciudades y las zonas rurales en la implantación de las redes de comunicación.

Mientras que en los Países Bajos, Alemania, el Reino Unido, Bélgica, Austria y Suecia, las tasas de penetración rural y nacional son idénticas o casi idénticas; sin embargo, en Finlandia, Bulgaria, Portugal, Rumanía y Grecia, donde la absorción rural fija se encuentra entre las más bajas de Europa, existen importantes brechas de 15-18 puntos porcentuales en comparación con la absorción nacional ("Digital Economy and Society Index Report 2018. Connectivity", 2018).

Si efectuamos una valoración de la implantación de las redes de Internet en España (cobertura $\geq 10$ Mbits), en función del tamaño del municipio, los resultados son completamente ilustrativos de la enorme brecha que existe con los vecinos que habitan en los municipios más pequeños (Cobertura de Banda ancha en España en el año 2018, 2018: 68-76):

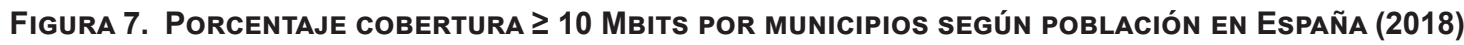

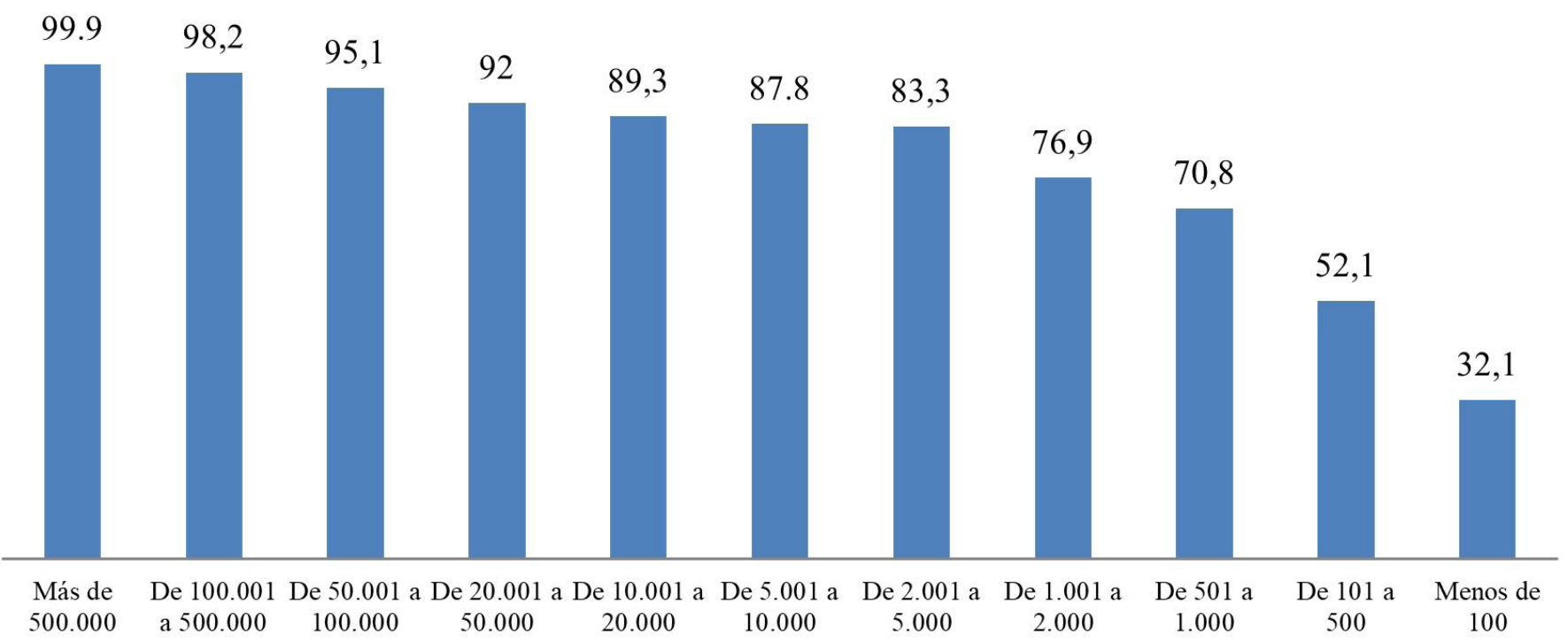

Fuente: elaboración propia a partir del "Informe Cobertura de Banda ancha en España en el año 2018”. 
Se destaca un descenso importante en la cobertura de Internet a partir de los municipios de 500 habitantes; lo cual es aún más significativo en las redes de más de 100 Mbits, que tiene un acusado descenso en los municipios de menos de 5.000 habitantes, fundamentalmente en los rurales, con una población de menos de 2.000 habitantes. De esta forma, la situación es la siguiente:

FiguRA 8. PORCENTAJE COBERTURA $\geq 100$ MBitS POR MUNICIPIOS SEGÚN POBLACIÓN EN ESPAÑa (2018)

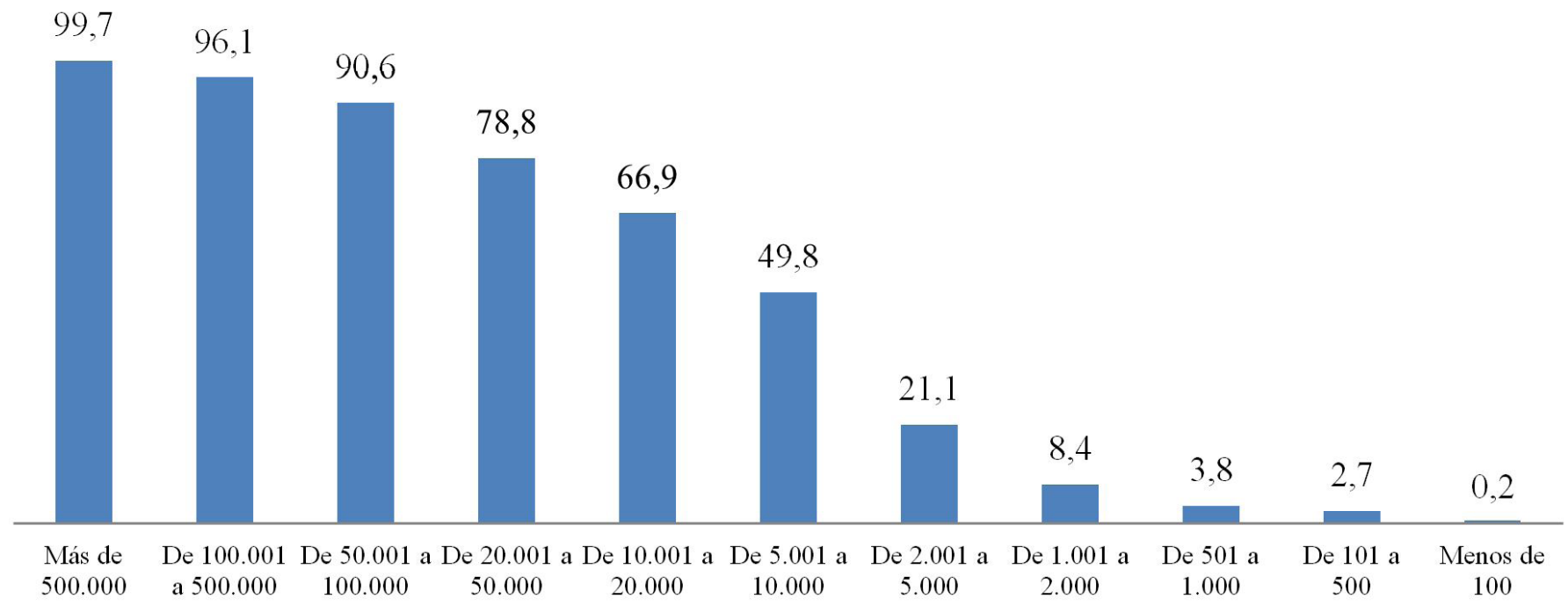

Fuente: elaboración propia a partir "Informe Cobertura de Banda ancha en España en el año 2018".

Los datos desagregados para la Comunidad de Castilla y León, y en relación con el resto de las Comunidades Autónomas no resultan especialmente ilusionantes; Castilla y León se encuentra por debajo de la media nacional. Mucho es el camino que aún queda por recorrer, pues esta Comunidad está por debajo de la media nacional en 15 puntos en cobertura de redes de $\geq 100$ Mbits.

De esta forma, la tabla que refleja la situación de la cobertura de Internet es la siguiente:

TABLA 3. Porcentaje de POBlación CON COBERTURA DE INTERNET

\begin{tabular}{lcccc}
\hline Comunidad Autónoma & $\mathbf{2}$ Mbps & $\mathbf{2 1 0}$ Mbps & $\geq \mathbf{3 0}$ Mbps & $\geq 100$ Mbps \\
\hline Castilla y León & $97,61 \%$ & $96,58 \%$ & $71,65 \%$ & $65,38 \%$ \\
\hline Media Nacional & $97,59 \%$ & $92,52 \%$ & $85,07 \%$ & $80,87 \%$ \\
\hline
\end{tabular}

Fuente: "Informe Cobertura de Banda ancha en España en el año 2018".

Y en lo que se refiere al porcentaje de población que puede utilizar Internet en las diversas provincias de Castilla y León, la situación es la siguiente:

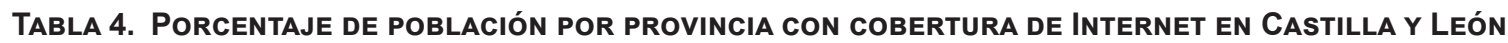

\begin{tabular}{lrccc}
\hline Provincia & $\mathbf{2}$ Mbps & $\mathbf{2 1 0}$ Mbps & $\mathbf{2 3 0}$ Mbps & $\geq 100$ Mbps \\
\hline Ávila & $97,00 \%$ & $82,57 \%$ & $52,59 \%$ & $41,11 \%$ \\
\hline Burgos & $96,58 \%$ & $86,26 \%$ & $76,29 \%$ & $70,39 \%$ \\
\hline León & $96,85 \%$ & $81,45 \%$ & $65,98 \%$ & $62,09 \%$ \\
\hline Palencia & $97,78 \%$ & $85,68 \%$ & $68,61 \%$ & $64,30 \%$ \\
\hline
\end{tabular}


REALA. Nueva Época - N.o 13, abril-septiembre 2020 - ISSN: 1989-8975 - DOI: 10.24965/reala.i13.10728 - [Págs. 110-130]

Castilla y León vacía (vaciada): esperando a Ulises

Santiago A. Bello Paredes

\begin{tabular}{lcccc}
\hline Provincia & $\mathbf{2}$ Mbps & $\mathbf{2 1 0}$ Mbps & $\mathbf{2 3 0}$ Mbps & $\geq \mathbf{1 0 0}$ Mbps \\
\hline Salamanca & $98,21 \%$ & $87,64 \%$ & $75,84 \%$ & $65,69 \%$ \\
\hline Segovia & $97,60 \%$ & $86,60 \%$ & $60,44 \%$ & $50,83 \%$ \\
\hline Soria & $95,04 \%$ & $81,58 \%$ & $65,44 \%$ & $58,05 \%$ \\
\hline Valladolid & $99,67 \%$ & $95,19 \%$ & $86,25 \%$ & $83,58 \%$ \\
\hline Zamora & $96,26 \%$ & $80,91 \%$ & $59,60 \%$ & $49,22 \%$ \\
\hline TOTAL NACIONAL & $\mathbf{9 7 , 5 9 \%}$ & $\mathbf{9 2 , 5 2} \%$ & $\mathbf{8 5 , 0 7 \%}$ & $\mathbf{8 0 , 8 7 \%}$ \\
\hline
\end{tabular}

Fuente: "Informe Cobertura de Banda ancha en España en el año 2018".

La situación evidencia que en todas las provincias de Castilla y León la conexión a Internet, en las velocidades de descarga de $\geq 10$ Mbits, $\geq 30$ Mbits $y \geq 100$ Mbits, se encuentra por debajo de la media nacional, a excepción de la provincia de Valladolid, y con un acusado nivel porcentual, en ocasiones de hasta casi un descenso de $40 \%$. En definitiva, la situación en Castilla y León es de una desesperante ausencia de implantación real y efectiva de las medidas para combatir la despoblación. Mientras, y por mucho que se teje y desteje el «ovillo de Penélope», sigue agravándose el problema; habrá que actuar ya para poner fin a esta dilatada espera, pues como nos ilustrase Homero en "La Odisea":

Oídme, mis ilustres pretendientes, los que habéis caído sobre esta casa para comer y beber de continuo durante la prolongada ausencia de mi esposo, sin poder hallar otra excusa que la intención de casaros conmigo y tenerme por mujer. Ea, pretendientes míos, os espera este certamen: pondré aquí el gran arco del divinal Ulises, y aquel que más fácilmente lo maneje, lo tienda y haga pasar una flecha por el ojo de las doce segures, será con quien yo me vaya, dejando esta casa á la que vine doncella, que es tan hermosa, que está tan abastecida, y de la cual me figuro que habré de acordarme aun entre sueños. (...). 404. Mas el ingenioso Ulises, tan luego como hubo tentado y examinado el gran arco por todas partes, cual un hábil citarista y cantor tiende fácilmente con la clavija nueva la cuerda formada por el retorcido intestino de una oveja que antes atara del uno y del otro lado: de este modo, sin esfuerzo alguno, armó Ulises el grande arco. (Homero, 1910: 286-293).

\section{REFERENCIAS BIBLIOGRÁFICAS}

ALARIO TRIGEROS, M.; MOLINERO HERNANDO, F.; MORALES PRIETO, E. (2018): "La persistencia de la dualidad real y el valor de la nueva ruralidad en Castilla y León (España)", en Investigaciones Geográficas, núm. 70, págs. 9-30. DOI: https://doi.org/10.14198/INGEO2018.70.01.

BELLO PAREDES, S. A. (2010): "La situación de las Entidades locales en los Estatutos de Autonomía reformados: especial referencia al marco estatutario de Castilla y León”, en Revista Jurídica de Castilla y León, núm. 20, págs. 345-380. URL: https://www.jcyl.es/web/jcyl/AdministracionPublica/es/Plantilla100Detalle/1215245063566/ Publicacion/1265032448602/Redaccion.

BELLO PAREDES, S. A. (2015): “Las entidades locales menores en Castilla y León: ¿Réquiem o revitalización?", en MERINO ESTRADA, V.; RIVERO ORTEGA, R. (dirs.): Derecho Local de Castilla y León, págs. 207-237. Madrid: lustel.

CALONGE VELÁZQUEZ, A. (2015): "La fusión de municipios, único instrumento de la Ley 27/2013, de 27 de diciembre, de racionalización y sostenibilidad de la Administración Local para la modificación de la planta municipal: una oportunidad perdida", en Revista de Estudios de la Administración Local y Autonómica (REALA). Nueva Época, núm. extraordinario, págs. 47-58. DOI: https://doi.org/10.24965/reala.v0iExtra.10222.

CARBONELL PORRAS, E. (2013): "La planta local: análisis general y perspectivas de reforma”, en DÍEZ SÁNCHEZ, J. J. (coord.): La planta del Gobierno Local: Actas del VIII Congreso de la Asociación Española de Profesores de Derecho Administrativo, págs. 17-59. Alicante 8 y 9 de febrero de 2013. Barcelona: Fundación Democracia y Gobierno Local.

CARBONELL PORRAS, E. (2018): "La alteración de términos municipales en la reforma local de 2013: crónica de un fracaso anunciado", en Revista de Estudios de la Administración Local y Autonómica (REALA). Nueva Época, núm. 9, págs. 5-19. DOI: https://doi.org/10.24965/reala.v0i9.10513.

COMISIÓN EUROPEA (2019): The Digital Economy and Society Index (DESI). Report 2018. Connectivity. Fecha de consulta: 13-09-2019. URL: https://ec.europa.eu/digital-single-market/en/desi. 
COMPANY VÁZQUEZ, A. M. (2012): "La ordenación del territorio en la Comunidad de Castilla y León y su sistema de planeamiento territorial, en especial, las directrices de ordenación del territorio y las directrices de ámbito subregional", en Revista Jurídica de Castilla y León, núm. 27, págs. 1-51. URL: https://www.jcyl.es/web/jcyl/ AdministracionPublica/es/Plantilla100Detalle/1215245063566/_1284222328704/Redaccion.

COSCULLUELA MONTANER, L. (2013): "Reforma de la Administración local. Una oportunidad de modificar la planta que no se puede perder", en Revista Española de Derecho Administrativo (REDA), núm. 157, págs. 11-19.

DIRECCIÓN GENERAL DE PRESUPUESTOS Y ESTADÍSTICA DE LA JUNTA DE CASTILLA Y LEÓN (2019): Evolución de la población por provincia, Castilla y León y España. 2001-2018. Fecha de consulta: 13-09-2019. URL: https://estadistica.jcyl.es/web/es/estadistica.html.

HOMERO (1910): La Odisea. SEGALÁ Y ESTALELLA, L. (trad.). Barcelona: Montaner y Simón.

LLOP, J. M."; IGLESIAS, B. M.; VARGAS, R.; BLANC, F. (2019): "Las ciudades intermedias: concepto y dimensiones", en Ciudades, núm. 22, págs. 23-43. DOI: https://doi.org/10.24197/ciudades.22.2019.23-43.

MARTÍN MATEO, R.; SOSA WAGNER. F. (1999): "Cincuenta años en la Administración Local”, en Revista de Administración Pública (RAP), núm. 150, págs. 285-316. URL: http://www.cepc.gob.es/publicaciones/revistas/revis taselectronicas? IDR=1\&IDN=148\&IDA=24268.

MARTÍNEZ LÓPEZ-MUÑIZ, J. L. (2006): "Cooperación y subsidiariedad intermunicipal”, en Revista de Estudios de la Administración Local y Autonómica (REALA), núm. 302, págs. 61-76. DOI: https://doi.org/10.24965/reala. vi302.9317.

MOLINA DE LA TORRE, I. (2019): "La despoblación en España: un análisis de la situación", en Instituto de Derecho Público de Barcelona (IDP). Fecha de consulta: 13-09-2019. URL: http://idpbarcelona.net/docs/foro/despoblacion. pdf.

PONS PORTELLA, M. (2016): "La población mínima de los nuevos municipios: estado de la cuestión tras la Ley de Racionalización y Sostenibilidad de la Administración Local”, en Revista de Estudios de la Administración Local y Autonómica (REALA). Nueva Época, núm. 5, págs. 106-119. DOI: https://doi.org/10.24965/reala.v0i5.10353.

PRIETO SARRO, I.; LÓPEZ TRIGAL, L. (1999): "Evolución demográfica reciente y ordenación del territorio en Castilla y León”, en Revista de Investigación Económica y Social de Castilla y León, núm. 1, págs. 87-102.

QUINTANA LÓPEZ, T. (2006): "Algunas cuestiones sobre la vertebración administrativa”, en Revista Jurídica de Castilla y León, núm. extraordinario. El Pacto Local, págs. 217-243. URL: https://www.jcyl.es/web/jcyl/ AdministracionPublica/es/Plantilla100Detalle/1215245063566/Publicacion/1212577533405/Redaccion.

QUINTANA LÓPEZ, T. (2014): "Debate previo a la reforma de la legislación del Estado de Régimen Local”, en QUINTANA LÓPEZ, T. (dir.); CASARES MARCOS, A. B. (coord.): La reforma del Régimen Local, págs. 23-71. Valencia: Tirant lo Blanch.

ROMANO, S. (1911): "Decentramento amministrativo", en PASQUALE STANISLAO, M. (dir.): Enciclopedia Giuridica Italiana, vol. IV, parte I-II-III, págs. 356-434. Milán: Società Editrice Libraria.

SECRETARÍA DE ESTADO PARA LA SOCIEDAD DE LA INFORMACIÓN Y LA AGENDA DIGITAL (2019): Informe cobertura de banda ancha en España en el año 2018. Fecha de consulta: 13-09-2019. URL: https://avancedigital. gob.es/banda-ancha/cobertura/Paginas/informes-cobertura.aspx.

SECRETARÍA DE ESTADO PARA LA SOCIEDAD DE LA INFORMACIÓN Y LA AGENDA DIGITAL (2019): Consulta pública sobre el programa de extensión de la banda ancha de nueva generación (PeBA-NGA) en el período 20192021. Fecha de consulta: 13-09-2019. URL: https://avancedigital.gob.es/es-es/Participacion/Paginas/Cerradas/ PEBA-NGA-2019-2021.aspx.

SOSA WAGNER, F. (2009): "Creación, fusión y supresión de municipios. El ejemplo alemán y la necesidad de un nuevo mapa municipal en el marco de las competencias de las Comunidades Autónomas”, en RODRÍGUEZ GONZÁLEZ, R. (coord.): Reformar la Administración Territorial: municipios eficientes y viables, págs. 69-98. Oleiros, La Coruña: Netbilo.

SOSA WAGNER, F.; DE MIGUEL GARCÍA, P. (1987): Creación, supresión y alteración de los términos municipales. Madrid: Instituto de Estudios de la Administración Local.

DE LA VALLINA VELARDE, J. L. (1961): "La desconcentración administrativa”, en Revista de Administración Pública (RAP), núm. 35, págs. 75-138. URL: http://www.cepc.gob.es/publicaciones/revistas/revistaselectronicas?IDR=1\&I $D N=35 \& I D A=22172$. 